\title{
Inflammatory processes have differential effects on claudins 2,3 and 4 in colonic epithelial cells
}

\author{
Shyam Prasad ${ }^{1}$, Roberto Mingrino ${ }^{1}$, Katri Kaukinen ${ }^{2}$, Katherine L Hayes ${ }^{1}$, \\ Robert M Powell ${ }^{1}$, Thomas T MacDonald ${ }^{1}$ and Jane E Collins ${ }^{1}$ \\ ${ }^{1}$ Division of Infection, Inflammation and Repair, Southampton General Hospital, University of Southampton \\ School of Medicine, Southampton, UK and ${ }^{2}$ Department of Internal Medicine and Medical School, University \\ of Tampere, Tampere, Finland
}

\begin{abstract}
Claudin proteins comprise a recently described family of tight junction proteins that differentially regulate paracellular permeability. Since other tight junction proteins show alterations in distribution or expression in inflammatory bowel disease (IBD) we assessed expression of claudins (CL) 2, 3 and 4 in IBD. CL 2 was strongly expressed along the inflamed crypt epithelium, whilst absent or barely detectable in normal colon. In contrast, $\mathrm{CL} 3$ and 4 were present throughout normal colonic epithelium and were reduced or redistributed in the diseased surface epithelium. In a T84-cell culture model of the gut barrier, paracellular permeability decreased with time after plating and correlated with a marked decrease in the expression of CL 2. Addition of IFN $\gamma / \mathrm{TNF} \alpha$ led to further decreases in CL 2 and 3, the redistrbution of CL 4 and a marked increase in paracellular permeability. Conversely, IL-13 dramatically increased CL 2, with little effect on CL 3 or 4 , but also resulted in increased paracellular permeability. Expression of CL 2 did not correlate with proliferation or junctional reorganisation after calcium ion depletion. Re-expression of CL 2 in response to IL-13 was inhibited by phophatidylinositol 3 kinase inhibitor, LY294002, which also restored the ion permeability to previous levels. CL 2 expression could be stimulated in the absence of IL-13 by activation of phospho-Akt in the phophatidylinositol 3 kinase pathway. These results suggest that INF $\gamma / T N F \alpha$ and IL-13 have differential effects on CL 2, 3 and 4 in tight junctions, which may lead to increased permeability via different mechanisms.
\end{abstract}

Laboratory Investigation (2005) 85, 1139-1162. doi:10.1038/labinvest.3700316; published online 11 July 2005

Keywords: claudin; tight junction; TNF $\alpha / \mathrm{INF} \gamma ; \mathrm{IL}-13$

The gut epithelial barrier separates the luminal contents from the mucosal immune system. The passage of antigens across this barrier must be regulated since inappropriate immune responses to the normal flora are believed to contribute to the development of inflammatory bowel disease (IBD). ${ }^{1}$ For example, between 10 and $20 \%$ presymptomatic Crohn's disease (CD) patients have been shown to have increased gut permeability, ${ }^{2,3}$ the noninflamed ileum of Crohn's patients exhibited increased permeability to proteins ${ }^{4}$ and increased intestinal epithelial permeability has been shown to precede clinical relapse in some asymptomatic CD

Correspondence: Dr JE Collins, PhD, Division of Infection, Inflammation and Repair, Southampton General Hospital, University of Southampton School of Medicine, Mailpoint 813, Tremona Road, Southampton SO16 6YD, UK.

E-mail: jec3@soton.ac.uk

Received 7 May 2005; revised 2 June 2005; accepted 4 June 2005; published online 11 July 2005 patients. ${ }^{5-7}$ Mutations in the human DLG 5 gene, encoding a protein involved in epithelial barrier differentiation, are a risk factor for $\mathrm{CD}^{8}$ Gut epithelial barrier dysfunction could allow luminal antigens to enter the lamina propria and plasma proteins to leak into the lumen. ${ }^{9}$ Therefore, increasing the understanding of mechanisms and interactions involved in the regulation of the intestinal barrier may give insights into inflammatory diseases of the gut.

An essential function of the intestinal epithelium is that it maintains tissue integrity while regulating gut permeability and this depends on the coordinate expression and interaction of proteins in cell-cell junctional complexes, including the tight junction, adherens junction and desmosome. ${ }^{10-15}$ Tight junctions, situated at the membrane between apical and lateral regions of polarised epithelial cells, selectively regulate the passage of molecules and ions via the paracellular pathway, ${ }^{16}$ and also restrict the lateral movement of molecules in the cell 
membrane. ${ }^{17,18}$ Proteins of the tight junction include integral membrane proteins claudins and occludin, cytoplasmic cytoskeletal linker proteins, ZO-1, ZO-2 and ZO-3, and also many signalling molecules such as aPKC, Rho proteins, PKC- $\zeta$, c-Yes and PI3kinase ${ }^{11,14}$ In addition, other proteins are associated with tight junctions that may have proliferative and differentiative capacity such as transcription factors, lipid phosphatases and cell cycle regulators. ${ }^{19}$

Claudins comprise a family of at least 24 proteins, whose differential expression and properties are believed to determine the tissue-specific variations in electrical resistance and paracellular ionic selectivity between epithelia. ${ }^{20,21}$ They are incorporated into the anastomosing intramembrane strands seen on freeze-fracture immunoreplicas of tight junctions. ${ }^{2-24}$ Interestingly, IBD is associated with reduced strand numbers and an increase in strand breakages and these changes are associated with a marked decrease in electrical resistance across the epithelium. $^{25}$ Junctional proteins show reduced expression or changes in distribution in gut inflammation. ${ }^{26-28}$ The dynamic nature of tight junctions is well demonstrated by the ability of cytokines and growth factors to modulate tight junction protein expression, regulate junction assembly and change epithelial permeability. ${ }^{29-33}$

It has been established for many years that the cytokine profile of CD is T-helper type 1 and shows increased expression of the cytokines, $\mathrm{TNF} \alpha$ and IFN $\gamma{ }^{34,35}$ The situation in ulcerative colitis (UC) is less clear. The expression of $\mathrm{TNF} \alpha$ is raised in macrophages in UC. ${ }^{36,37}$ Recently, however, mucosal NK-like T cells from UC patients have been shown to produce elevated amounts of a signature T-helper type 2 cytokine, IL- $13 .^{38}$

In this study, we have assessed the expression of claudins 2, 3 and 4 in normal colon and from patients with IBD. We found that while claudins 3 and 4 were sometimes decreased or redistributed in disease, the expression of claudin 2 was markedly increased in all cases of CD and UC examined. We have utilised T84 cells to model the epithelial barrier. ${ }^{29}$ T84 cells have structural similarities to intestinal crypt cells ${ }^{39}$ and increase their tight junction strand number with time in monolayer culture that correlates with increased resistance. ${ }^{40}$ Since intestinal crypt cells are believed to be leaky relative to surface cells $s^{41-43}$ it is unclear how the developing monolayer culture model relates to the differentiation of cells in vivo, but it may be representative of the more differentiated epithelium in relation to tight junction assembly. We utilised the T84 monolayers at 2 weeks confluence when the TER was reproducible, $\sim 600 \Omega \mathrm{cm}^{2}$, and the monolayer intact and viable (as checked by Trypan blue staining and LDH assays on replicate cultures).

We found that treatment with TNF $\alpha / \mathrm{IFN} \gamma$ or IL-13 led to increased paracellular permeability via different effects on claudin proteins with claudin 4 being redistributed in response to $\mathrm{TNF} \alpha / \mathrm{IFN} \gamma$ and claudin 2 being increased only in response to IL-13. The PI3K-signalling pathway is implicated in the T84 response to IL-13. Thus in inflammatory sites there may be multiple regulatory inputs affecting paracellular permeability via different mechanisms involving claudin proteins.

\section{Materials and methods}

\section{Ethical Approval}

All aspects of the study were approved by the Southampton Joint University and Hospitals Ethics Committee, and written informed consent was obtained from each subject.

\section{Glycol Methacrylate Embedding}

Biopsies were taken at colonoscopy from the sigmoid colon in all normal patients, those with UC and as near to the sigmoid as possible in Crohn's colitis patients. Control biopsies from normal patients were essential to ensure that differences observed in disease samples were not due to handling, crushing or processing artefacts. Biopsies were placed into ice-cold acetone containing $2 \mathrm{mM}$ phenyl methyl sulphonyl fluoride and $20 \mathrm{mM}$ iodoacetamide (all chemicals from Sigma unless otherwise stated) and fixed overnight at $-20^{\circ} \mathrm{C}$. The fixative was replaced with acetone at room temperature for $15 \mathrm{~min}$ and then with methyl benzoate (Sigma) at room temperature for a further $15 \mathrm{~min}$. The tissue was then embedded in glycol methacrylate $\operatorname{resin}^{44}$ in Taab flat bottomed capsules, polymerised overnight at $4{ }^{\circ} \mathrm{C}$ and stored at $-20^{\circ} \mathrm{C}$. The sections were cut using a Reichert Jung motorised microtome and floated out into $0.5 \%$ ammonia for $1 \mathrm{~min}$. The sections were collected onto poly-Llysine-coated slides and left to dry for $1 \mathrm{~h}$ before immunostaining.

\section{Immunohistochemistry}

Human biopsies of UC and CD and control normal mucosa (from resections for cancer) were processed (Table 1). Sections were treated with $0.1 \%$ sodium azide and $0.3 \%$ hydrogen peroxide and blocked for 30 min in 1\% BSA with 5\% FBS in TBS before $2 \mathrm{~h}$ incubation with primary antibodies: rabbit antihuman claudin 2 (1:40), rabbit anti-human claudin 3 (1:50), mouse anti-human claudin 4 (1:400) (all from Zymed/Cambridge BioScience, Cambridge, UK) or mouse isotype-negative controls for the monoclonals or normal rabbit IgG for the polyclonals (Dako Ltd) at similar Ig concentrations to the primary antibodies. After TBS washes, biotinylated rabbit anti-mouse $(1: 300)$ or guinea pig anti-rabbit (1:1200) (Dako Ltd) was applied for $90 \mathrm{~min}$, followed by streptavidin $(0.5 \% \mathrm{v} / \mathrm{v})$ and biotin-peroxidase $(0.5 \% \mathrm{v} / \mathrm{v})$ complexes (both from 
Table 1 Analysis of immunohistochemical staining in the tight junctions of IBD biopsies stained with claudin 2,3 and 4 antibodies

\begin{tabular}{|c|c|c|c|c|}
\hline \multicolumn{5}{|l|}{ Claudin 2} \\
\hline Diagnosis & NC & UCI & UCA & CD \\
\hline No. cases & 4 & 4 & 12 & 5 \\
\hline Mean age & 45 & 46 & 45 & 53 \\
\hline Male: Female & $3: 1$ & $2: 2$ & $8: 4$ & $3: 2$ \\
\hline \multicolumn{5}{|l|}{ Median ( $p$ vs NC) } \\
\hline Crypt TJ & 0 & $39.5(0.02)$ & $78.5(0.01)$ & $65(0.01)$ \\
\hline Surface TJ & 2 & $2(0.88)$ & $3(0.66)$ & $1(1.00)$ \\
\hline \multicolumn{5}{|l|}{ Claudin 3} \\
\hline Diagnosis & NC & UCI & UCA & $\mathrm{CD}$ \\
\hline No. cases & 4 & 4 & 12 & 6 \\
\hline Mean age & 45 & 46 & 45 & 53 \\
\hline Male: Female & $3: 1$ & $2: 2$ & $8: 4$ & $4: 2$ \\
\hline \multicolumn{5}{|l|}{ Median ( $p$ vs NC) } \\
\hline Crypt TJ & 98.5 & $99(0.66)$ & $98(0.46)$ & $95(0.99)$ \\
\hline Crypt Lat Memb & 92 & $96.5(0.14)$ & $73.5(0.07)$ & $68(0.05)$ \\
\hline Surface TJ & 96 & $44.5(0.02)$ & $54(0.00)$ & $21(0.01)$ \\
\hline Surface Lat Memb & 92 & $40.5(0.11)$ & $31(0.01)$ & $36(0.09)$ \\
\hline \multicolumn{5}{|l|}{ Claudin 4} \\
\hline Diagnosis & NC & UCI & UCA & CD \\
\hline No. cases & 4 & 4 & 13 & 5 \\
\hline Mean age & 45 & 46 & 46 & 48 \\
\hline Male: Female & $3: 1$ & $2: 2$ & $9: 4$ & $3: 2$ \\
\hline \multicolumn{5}{|l|}{ Median ( $p$ vs $N C$ ) } \\
\hline Crypt TJ & 95.5 & $96.5(0.38)$ & $95(0.60)$ & $90.5(0.25)$ \\
\hline Crypt Lat Memb & 95 & $74.5(0.77)$ & $81(0.09)$ & $64.5(0.19)$ \\
\hline Surface TJ & 79 & $32(0.15)$ & $40(0.07)$ & $79(0.54)$ \\
\hline Surface Lat Memb & 90.5 & $55(0.06)$ & $51.5(0.10)$ & $78(0.46)$ \\
\hline
\end{tabular}

Assessment of the staining in the tight junctions (TJ) and lateral membranes (Lat Memb)(claudins 3 and 4) of colonic biopsies from patients with normal colon (NC), quiescent ulcerative colitis (UCI), active ulcerative colitis (UCA) and Crohn's Disease. Cases for each category are described above the analysis of each antibody stain. The data shows that claudin 2 staining is significantly increased in IBD compared with normal. $P$-values of disease compared to normal are shown in parentheses.

BioGenex/Menarini Diagnostics, Wokingham, UK) for $90 \mathrm{~min}$ and 3,3'-diaminobenzidine (BioGenex) for $10 \mathrm{~min}$. The slides were rinsed, counterstained with Mayer's haematoxylin, dehydrated and mounted in xylene/dibutyl phthalate (DPX). Cases were examined by light microscopy on a Nikon Eclipse E600 microscope, photographed using a Nikon Coolpix 950 digital camera and processed with Adobe Photoshop 6.0 software (Adobe Systems Incorporated, CA, USA).

\section{Analysis of Immunohistochemical Staining}

The identities and diagnoses of the cases studied remained anonymous for the subsequent analysis. All the sections were examined by light microscopy at magnifications of $\times 200$ and $\times 400$. For each antibody studied, five randomly selected fields containing surface epithelium and five containing crypt epithelium were examined. Within each field the 20 left-most epithelial cells were examined and the number staining positive in the tight junction region was counted. Summation of the numbers from all five fields thus yielded a percentage of tight junctions staining positive. As in most cases the epithelial staining for claudins 3 and 4 also involved the lateral membranes, the percentage of crypt and surface epithelial cells staining positive at this location was also computed. Cases were categorised diagnostically and compared statistically using the Mann-Whitney $U$-test with significance at $P=<0.05$.

\section{Epithelial Cell Isolation}

Resected colonic tissue $\left(10 \mathrm{~cm}^{2}\right)$ from UC, CD and controls was dissected from the submucosa, chopped and stirred, in $0.5 \mathrm{mM}$ dithiothreitol (DTT) in Hank's Balanced Salt Solution (HBSS, pH7.3; Life Technologies) $5 \mathrm{~min}$ at $4^{\circ} \mathrm{C}$ followed by $20 \mathrm{~min}$ at $4^{\circ} \mathrm{C}$ in isolation buffer ${ }^{45}(27 \mathrm{mM}$ trisodium citrate, $5 \mathrm{mM}$ di-sodium hydrogen orthophosphate, $96 \mathrm{mM}$ sodium chloride, $8 \mathrm{mM}$ potassium hydrogen orthophosphate, $1.5 \mathrm{mM}$ potassium chloride, $55 \mathrm{mM}$ $d$-sorbitol, $44 \mathrm{mM}$ sucrose, $0.5 \mathrm{mM}$ dithiothreitol; pH7.3). The tissue pieces were separated with a strainer and returned to fresh isolation buffer. Loosened cells were centrifuged and resuspended in $0.5 \mathrm{ml}$ of isolation buffer, assessed by light microscopy and snap frozen in liquid nitrogen. The tissue pieces were shaken in buffer to free intact or partially broken crypts from the underlying matrix, and the process was repeated until no more crypts were released.

\section{SDS-PAGE and Western Blotting}

Cell pellets were solubilised in an equal volume of sample buffer $(100 \mathrm{mM}$ Tris $\mathrm{HCl}, 5 \%$ sodium dodecyl sulphate, $20 \%$ glycerol, $5 \mathrm{mM}$ dithiothreitol (DTT), $10 \% \mathrm{v} / \mathrm{v}$ mammalian cell protease inhibitor cocktail from Sigma). T84 cell monolayers were lysed in SDS sample buffer with phosphatase and kinase inhibitors (1 mM EDTA, $1 \mathrm{mM}$ EGTA, $20 \mathrm{mM}$ sodium pyrophosphate, $1 \mathrm{mM}$ sodium fluoride, $1 \mathrm{mM}$ activated sodium orthovanadate; all from Sigma). Protein concentrations were determined by the bicinchoninic acid (BCA) method (Perbio Science Ltd, Tattenhall, UK). DTT and bromophenol blue concentrations were adjusted to $100 \mathrm{mM}$ and $0.1 \% \mathrm{w} / \mathrm{v}$, before running on 10 or $12.5 \%$ denaturing polyacrylamide gels ${ }^{46}$ prior to transfer. Membranes were probed sequentially with rabbit anti-human claudin 2, rabbit anti-human claudin 3 , mouse anti-human claudin 4 (all from Zymed), mouse anti-human phospho-Akt (Ser473) and rabbit antihuman Akt (latter two from New England Biolabs Ltd, Hitchin, UK). All blots were probed with mouse anti-human cytokeratin 19 (Dako) as a loading control for epithelial proteins and this was used to 
normalise all protein reactivities in order to ensure validity of quantitative blotting data. Mouse nonspecific isotype control antibody (Dako) for the monoclonals or normal rabbit control IgG (Dako) for the polyclonals, at similar Ig concentrations to the primary antibodies, were also used to ensure specificty. The secondary antibodies were HRPrabbit anti-mouse and HRP-goat anti-rabbit (Dako) with the ECL Plus kit (Amersham Biosciences). Membranes were stripped by incubating in a solution of $2 \% \quad \mathrm{w} / \mathrm{v}$ SDS, $62.5 \mathrm{mM}$ tris $\mathrm{HCl}$, $100 \mathrm{mM}$ 2-mercaptoethanol (pH 6.7; Sigma) for $30 \mathrm{~min}$ at $65^{\circ} \mathrm{C}$. Blots were carried out under identical conditions for each experiment/antibody, unless stated and scanned, quantified densitometrically with Gene Gnome system and Gene Snap software (Syngene Corporation, Cambridge, UK) and normalised to cytokeratin 19 for equal epithelial protein loading.

\section{T84 Cell Culture, Cytokines, Inhibitors, Calcium-Free and Lithium Chloride}

T84 cells were subcultured on glass coverslips or $0.4 \mu \mathrm{m}$ pore BIOCOAT Control Cell Culture Inserts (BD Biosciences, Oxford, UK), precoated with type I collagen (Roche Products Ltd, Welwyn Garden City, $\mathrm{UK})$ and maintained at $37^{\circ} \mathrm{C}$ in $5 \% \quad \mathrm{CO}_{2}$ in Dulbecco's-modified eagle medium (DMEM)/Hams Nutrient F12 Mix, supplemented with 10\% FBS, $100 \mathrm{U} / \mathrm{ml}$ penicillin, $100 \mu \mathrm{g} / \mathrm{ml}$ streptomycin and $2 \mathrm{mM}$ glutamine (all from Invitrogen). Cytokines (R\&D Systems, Abingdon, UK) were dissolved in PBS with 0.1\% BSA and LY294002 (Merck Biosciences Ltd, Nottingham, UK) solubilised in DMSO to make a $50 \mathrm{mM}$ stock and stored at $-20^{\circ} \mathrm{C}$.

Control monolayers were incubated in medium with vehicle alone. Medium with IFN $\gamma(100 \mathrm{ng} / \mathrm{ml})$ and $\mathrm{TNF} \alpha(1 \mathrm{ng} / \mathrm{ml})$ or IL-13 $(2 \mathrm{ng} / \mathrm{ml})$ alone or with 5,20 or $50 \mu \mathrm{M}$ Ly 294002 or $20 \mathrm{mM} \mathrm{LiCl}$ was replaced 12 hourly. For some phospho-Akt blots and quantitative RT-PCR, cells were preincubated for $16 \mathrm{~h}$ in serum-free medium (SFM) with 1\% BSA, transferrin $(5 \mathrm{ng} / \mathrm{ml})$ and sodium selenite $(5 \mathrm{ng} / \mathrm{ml})$ prior to incubation in SFM with IL-13 and/or inhibitors or with $\mathrm{Li} \mathrm{Cl}$. Cell toxicity was assessed by lactate dehydrogenase release into medium (Roche). To expose monolayers to a low calcium environment, they were rinsed twice with PBS $\pm 1.2 \mathrm{mM} \mathrm{Ca}^{2+}$ and

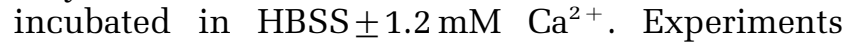
were performed three times minimum normally with $n=6$ filters each time for controls or treatments to facilitate staining, protein/RNA analysis or fluorescein isothiocyanate (FITC)-dextran measurements.

\section{Measurement of Transepithelial Electrical Resistance}

In filter experiments, the medium was changed at least $2 \mathrm{~h}$ before measuring transepithelial epithelial resistance (TER) using an EVOM voltohmeter and an STX2 electrode (World Precision Instruments, Stevenage, UK). The electrode was soaked in $70 \%$ ethanol and rinsed with sterile D-PBS prior to use. The electrical resistance between the lower compartment (well) and the upper compartment (filter insert) was measured. Triplicate measurements were taken, ensuring that the temperature remained close to $37^{\circ} \mathrm{C}$ to avoid alterations in resistance due to temperature changes ${ }^{47,48}$ and the mean was calculated. Three readings were also taken from a collagen-coated insert that contained medium but no cells and had been treated in exactly the same way as the experimental inserts. The mean of these was subtracted from those obtained for the inserts containing cells to give a true TER for the cell monolayer alone. The measurements were expressed as $\Omega \mathrm{cm}^{2}$ by multiplying by the area of the filter inserts $\left(0.9 \mathrm{~cm}^{2}\right)$. Unless otherwise stated, 2-week-old monolayers of cells on filter inserts, of mean TER approximately $600 \Omega \mathrm{cm}^{2}$, or greater were used.

\section{Assessment of Epithelial Barrier Integrity}

The passage of uncharged molecules across T84 monolayers was assessed using apical fluorescein isothiocyanate (FITC)-conjugated $4 \mathrm{kDa}$ dextran (Sigma) $^{48}$ with cells cultured on $0.9 \mathrm{~cm}^{2}$ filter inserts. The medium on the cells was changed $1 \mathrm{~h}$ before the apical medium was replaced with $0.2 \%$ FITC-dextran. After incubation for $3 \mathrm{~h}$ the basal medium was removed for the assay. Three $100 \mu \mathrm{l}$ samples were used for each monolayer examined. Fluorescence was measured in opaque 96-well Nunc $^{\text {TM }}$ plates (Fisher Scientific UK Ltd, Loughborough, UK) using an FLX-800 Fluorimeter (Bio-Tek Instruments Inc., Winooski, VT, USA) at excitation and emission wavelengths of 490 and $520 \mathrm{~nm}$, respectively for a mean of 10 measurements per sample. A standard curve was constructed by measuring the fluorescence obtained from FITCdextran solutions of known concentrations in cell culture medium.

\section{Immunofluorescent Staining of Cells on Coverslips and Filters}

Filters or coverslips were dried, fixed in acetone $10 \mathrm{~min}$, incubated overnight at $4^{\circ} \mathrm{C}$ with primary antibodies in PBS-1\%BSA: rabbit anti-human claudin 2 (1:150), rabbit anti-human claudin 3 (1:200), mouse anti-human claudin 4 (1:200), mouse antiZO-1 (1:250) (Zymed) and mouse anti-human Ki67 (1:25) (Dako) or negative control mouse isotype or normal rabbit IgG antibodies at similar concentrations to primary antibodies. The monolayers were washed and incubated with goat anti-rabbit Alexa-Fluor-488 (1:1000), goat anti-mouse AlexaFluor-546 (1:1000) (Molecular Probes Europe, Leiden, Netherlands) or FITC-conjugated swine 
anti-mouse antibody (1:60) (Dako) for $90 \mathrm{~min}$. Nuclei were counterstained with TO-PRO-3-iodide (Molecular Probes) before mounting in antifadant (Citifluor Ltd, London, UK) containing 0.1\% Mowiol and viewing by confocal laser scanning microscopy (Leica SP2 and software).

\section{Immunostaining of Whole Mounts of Isolated Epithelial Cells}

Isolated surface or crypt epithelium, from human colonic tissue was retrieved from isolation buffer by centrifugation and $100 \mu \mathrm{l}$ pellet was diluted with 4 volumes of PBS. Then, $100 \mu$ l aliquots were loaded onto a cytospin 3 (Shandon) and spun for $1 \mathrm{~min}$ at $150 \mathrm{rpm}$ onto poly-L-lysine-coated slides. The cells were left to dry for $20 \mathrm{~min}$ and then fixed using $2 \%$ formaldehyde in PBS for $30 \mathrm{~min}$. The slides were then washed and excess aldehydes were quenched with $0.1 \mathrm{M}$ glycine in PBS for $5 \mathrm{~min}$ and washed again. The cells were permeabilised with $0.1 \%$ Triton X-100 for $20 \mathrm{~min}$ followed by $90 \mathrm{~min}$ room temperature incubation in rabbit anti-human claudin 2 (1:150) (Zymed), monoclonal anti-ZO-1 primary antibody (1:250) (Zymed) or controls as described above, diluted in 1\% BSA in $\mathrm{PBS}$ at room temperature for $90 \mathrm{~min}$. The slides were then washed and incubated in goat anti-rabbit Alexa-Fluor-488 (1:1000) (Molecular Probes) for another $90 \mathrm{~min}$ at room temperature. Slides were then rinsed in PBS for $5 \mathrm{~min}$ and counterstained with $4 \mu \mathrm{g} / \mathrm{ml}$ 7-aminoactinomycin D (Sigma) in PBS for $10 \mathrm{~min}$ prior to washing and mounting in Mowiol (Polyscience Inc., Macclesfield, Cheshire, UK). The slides were viewed with a Leica TCS SP2 confocal microscope and analysed with Leica Confocal Software.

\section{Quantitative Reverse Transcriptase-Mediated PCR}

Total RNA was extracted from tissue epithelial cells using Trizol (Gibco) and from T84 cells using an RNeasy kit (Qiagen), according to the manufacturers' instructions and treated with DNase I using a DNA-Free kit (Ambion) to remove contaminating DNA. 0.5-1.0 $\mu$ g RNA was preincubated at $80^{\circ} \mathrm{C}$ with $0.5 \mu \mathrm{g}$ oligo dT (Promega), prior to first-strand cDNA synthesis in $20 \mu \mathrm{l}$ reactions containing $50 \mathrm{mM}$ Tris$\mathrm{HCl} \mathrm{pH} 8.3,75 \mathrm{mM} \mathrm{KCl}, 3 \mathrm{mM} \mathrm{MgCl}_{2}, 10 \mathrm{mM}$ DTT, $500 \mu \mathrm{M}$ dNTPs, $20 \mathrm{U}$ Rnasin ribonuclease inhibitor and $100 \mathrm{U}$ MMLV reverse transcriptase (all from Promega) by incubation at $37^{\circ} \mathrm{C}, 1 \mathrm{~h}$, followed by enzyme inactivation at $78^{\circ} \mathrm{C}, 10 \mathrm{~min}$. Negative controls were carried out without MMLV (RTsamples). PCR reactions contained cDNA (25 ng RNA), $1 \times$ buffer, $200 \mu \mathrm{M}$ dNTPs, $5 \mathrm{mM} \mathrm{MgCl}_{2}$, $0.025 \mathrm{U} / \mu \mathrm{l}$ Hot Goldstar DNA polymerase (Eurogentec Ltd, Romsey, UK) and $1 \mu \mathrm{M}$ each forward and reverse primers with $125 \mathrm{nM}$ internal probe or $0.0049 \%$ SYBR green (Eurogentec) and $9.85 \mu \mathrm{g} / \mathrm{ml}$ fluorescein (BioRad). Reactions were incubated at $95^{\circ} \mathrm{C}$ for $9 \mathrm{~min}$ then cycled $45-50$ times at $95^{\circ} \mathrm{C}, 15 \mathrm{~s}$; $60^{\circ} \mathrm{C}, 1 \mathrm{~min}$ in an iCycler (BioRad). Duplicate samples were analysed in triplicate. The primers for the claudin 2 gene (CLDN2) were as follows: sense, 1376-TCCCACTGACTGACCCTCTGT-1396, antisense, 1468-GCCACTGCTTCTCCTTCCCAT-1448, NCBI accession NM_020384. SYBR green incorporation was quantified at absorption and emission wavelengths of 490 and $520 \mathrm{~nm}$. Analysis confirmed a single PCR product at the predicted melting temperature. The housekeeping genes (HK) were GAPDH and ubiquitin $\mathrm{C}$ (UBC) and were simultaneously quantified using internal probes $5^{\prime}$-labelled with a different fluorophore for each gene (FAM-490 or VIC-530, Eurogentec). Reactions were performed in duplicate and the average cycle threshold $\left(C_{\mathrm{T}}\right)$ for each sample was derived for claudin 2, GAPDH and UBC. As the $C_{\mathrm{T}}$ is an exponential function, the geometric mean was calculated to give a single $\mathrm{HK} C_{\mathrm{T}}$ value. The relative level of claudin 2 mRNA was then normalised to the HK $C_{\mathrm{T}}$ value to give the $\Delta C_{\mathrm{T}}$ value for each mRNA sample. $\Delta C_{\mathrm{T}}$ values for disease samples or cytokine treatments were compared to the median $\Delta C_{\mathrm{T}}$ value for normals or controls using the $\Delta \Delta C_{\mathrm{T}}$ method. Assays were performed minimum three times.

\section{Statistical Analysis}

A Student's $t$-test (group mean comparison test) was used to compare TER or FITC-dextran passage, with Satterthwaite's correction for unequal variances where appropriate. Multiple groups were compared by a one-way analysis of variance (ANOVA) with Bonferroni's correction for multiple comparisons where appropriate. Stata-8 software was used and statistical significance $P<0.05$.

\section{Results}

Claudin 2 Expression is Increased in Colonic Epithelia of Inflammatory Bowel Disease

Claudin 2 staining was barely detectable or absent in biopsies from normal colon. Staining was strongly positive on the crypt epithelium of all cases of CD and both active and inactive UC (Figure 1). Staining was particularly striking in hyperplastic UC crypts and also appeared sporadically at the surface epithelium in some cases of active UC. Positive staining was located predominantly at the tight junction region of the epithelial cells. Detailed analysis of claudin 2 staining (Table 1) showed that the increase in claudin 2 was statistically significant in the crypt areas of UC and CD samples and increased with severity of inflammation in UC biopsies. Conversely, strong immunostaining for claudin 3 (Figure 2) and 4 (Figure 3) was seen in the crypt and surface epithelium of normal colon. This staining was seen in junctional and basolateral 

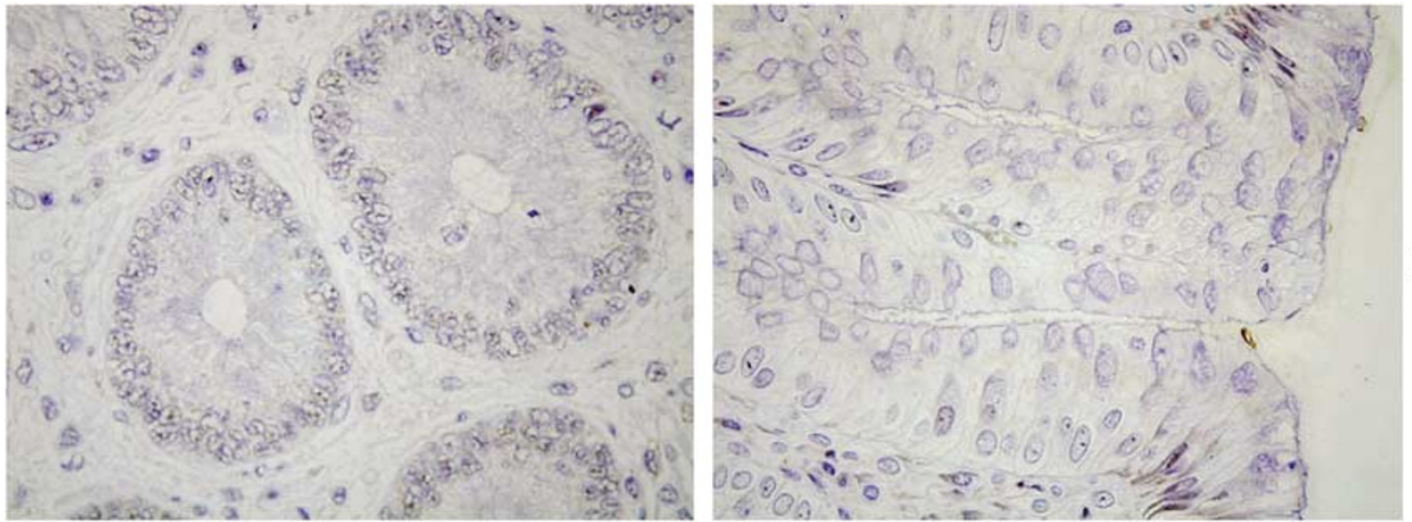

Normal
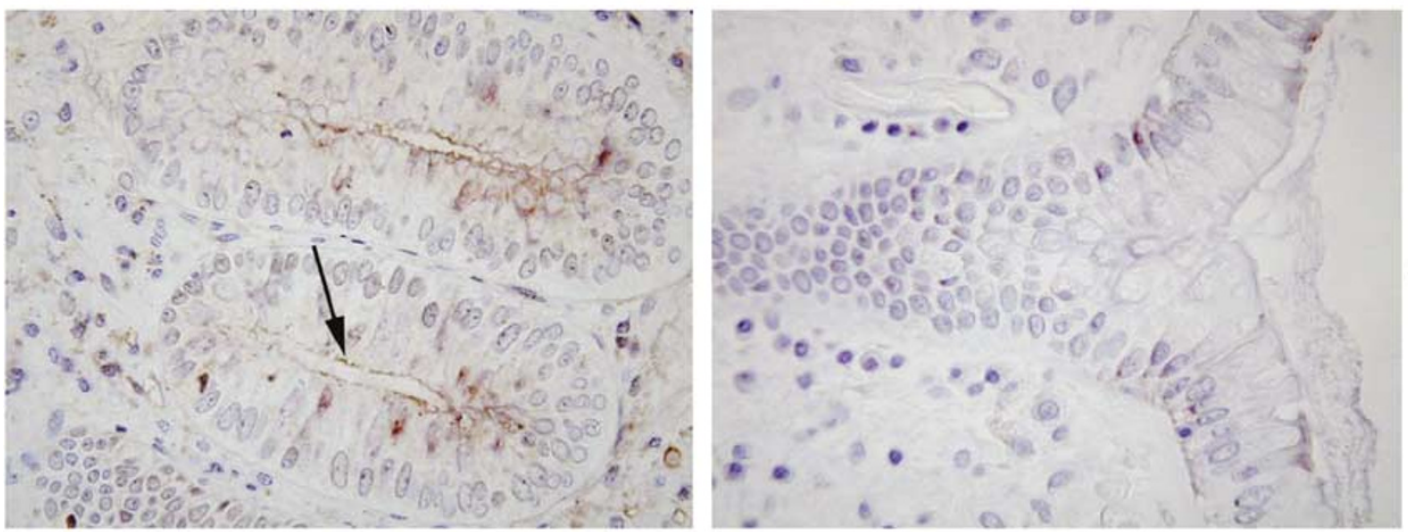

Crohn's
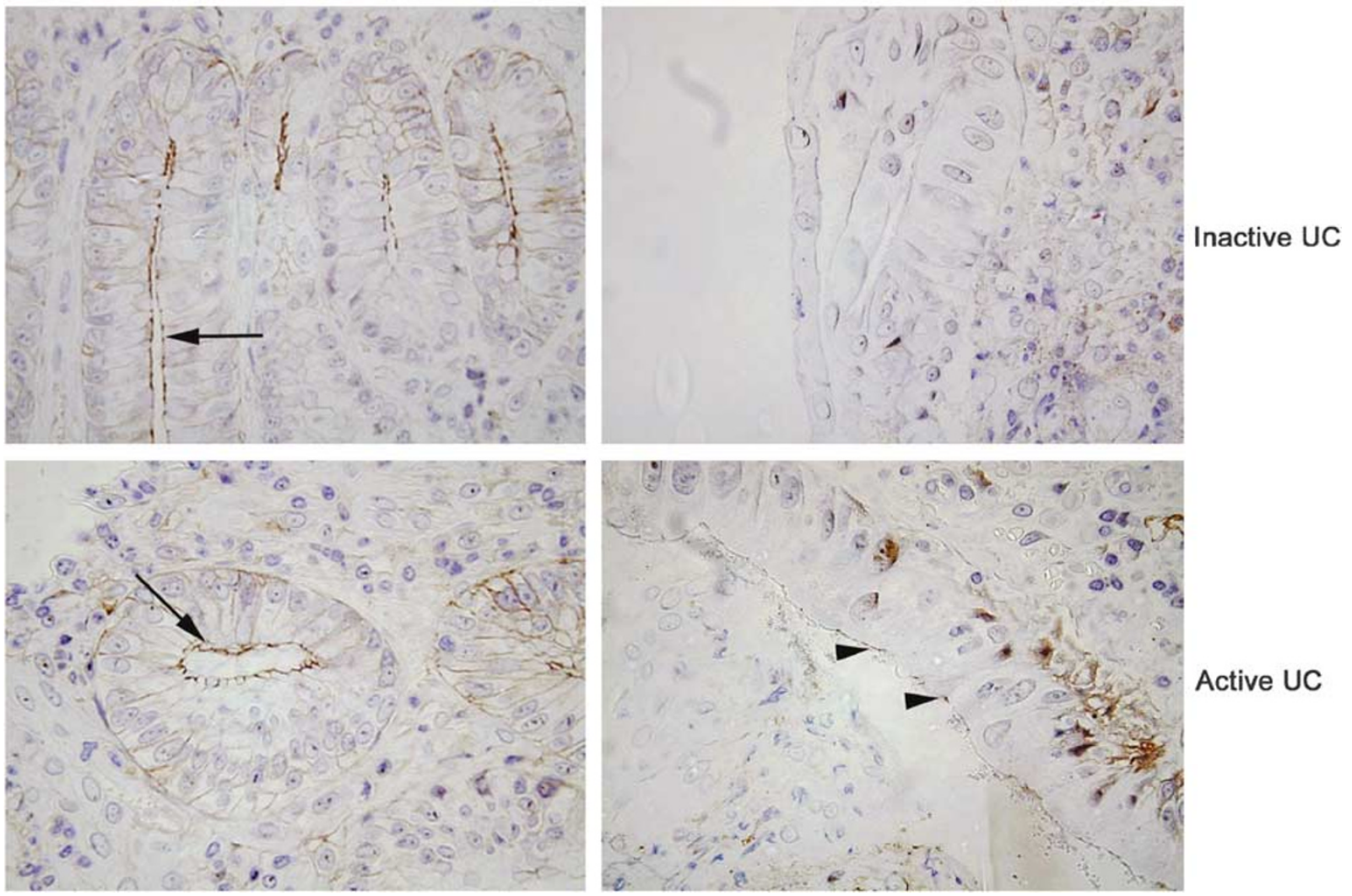

Active UC

Figure 1 Representative photomicrographs of claudin 2 staining in colonic biopsies. Epithelial crypt areas are shown on the left with surface epithelial areas on the right. Claudin 2 staining is not seen in this normal tissue, but there is strong staining of tight junctions in UC and CD crypt epithelium (arrows) and sporadic staining in UC surface epithelium (arrowheads). Original magnification $\times 400$. 

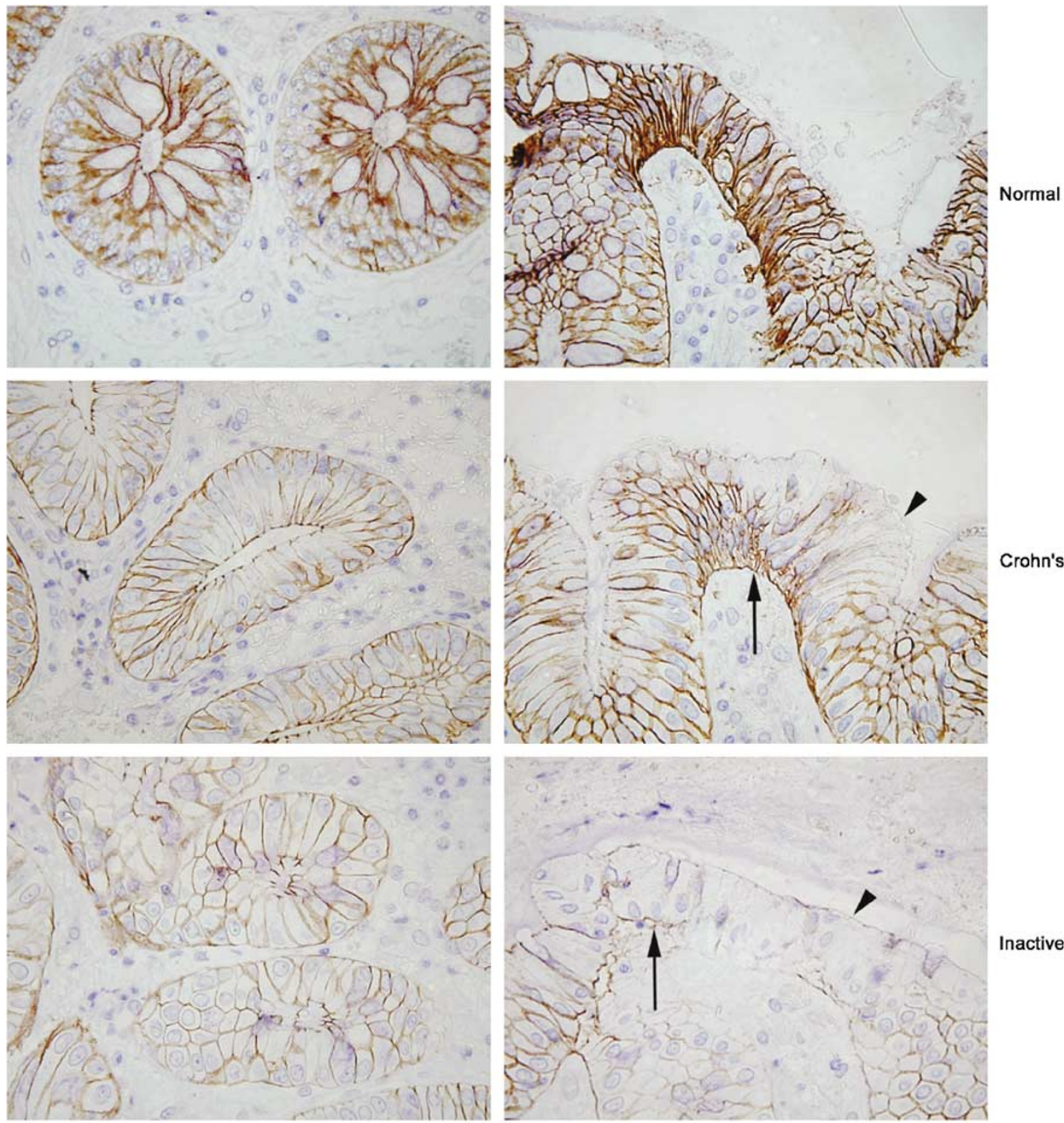

Crohn's

Inactive UC
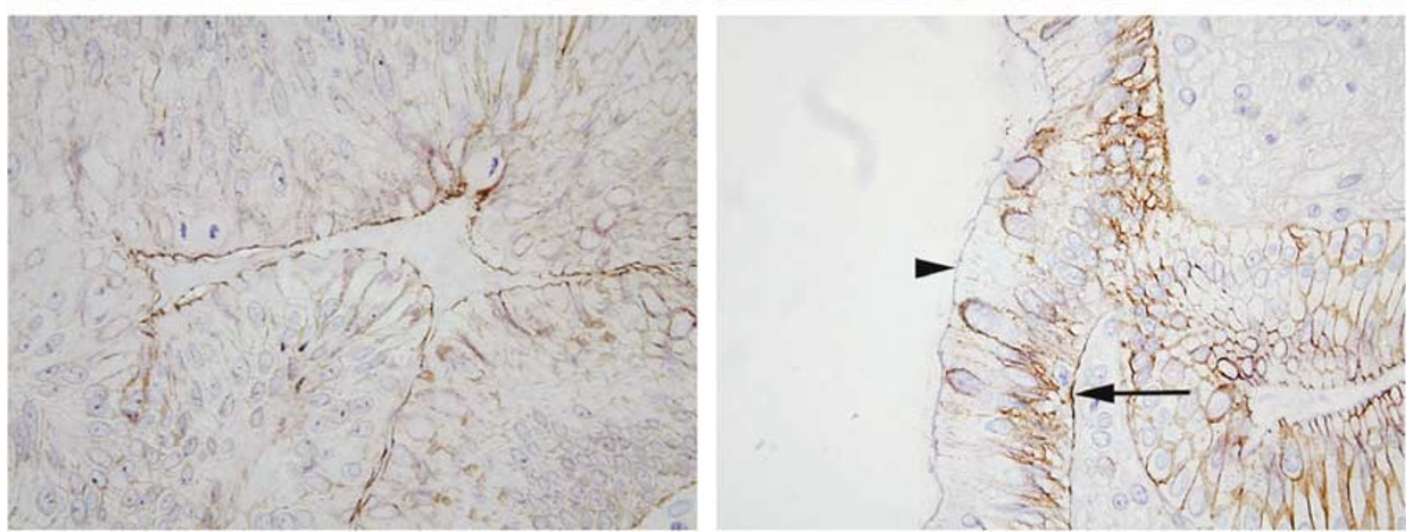

Active UC

Figure 2 Representative photomicrographs of claudin 3 staining in colonic biopsies. Epithelial crypt areas are shown on the left with surface epithelial areas on the right. Claudin 3 staining is present in normal colonic epithelium in junctional and lateral cell membranes whereas, in IBD, staining is reduced in surface epithelium in apical cell regions (arrowheads), while being retained at the basolateral membranes (arrows). Original magnification $\times 400$. 

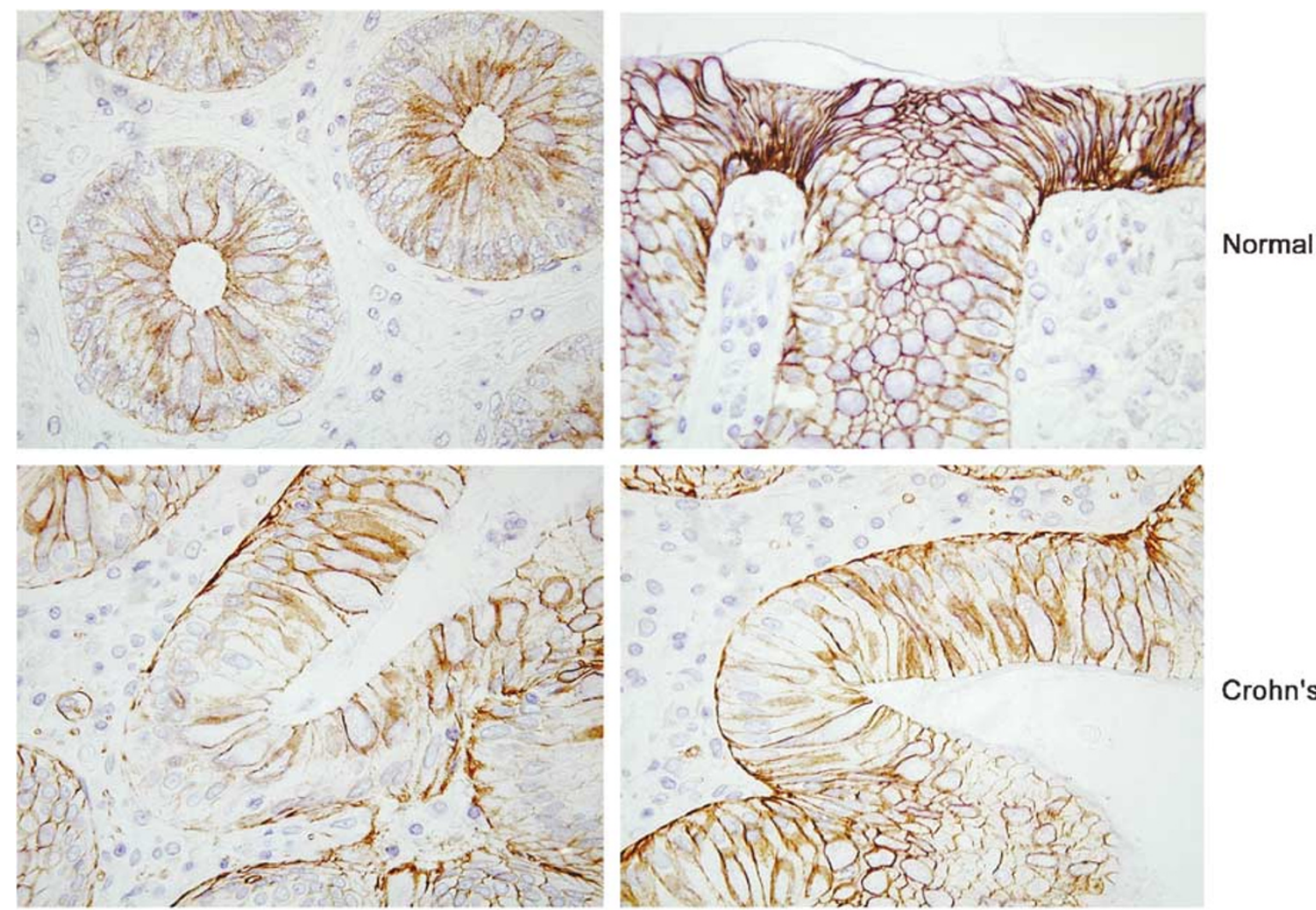

Crohn's
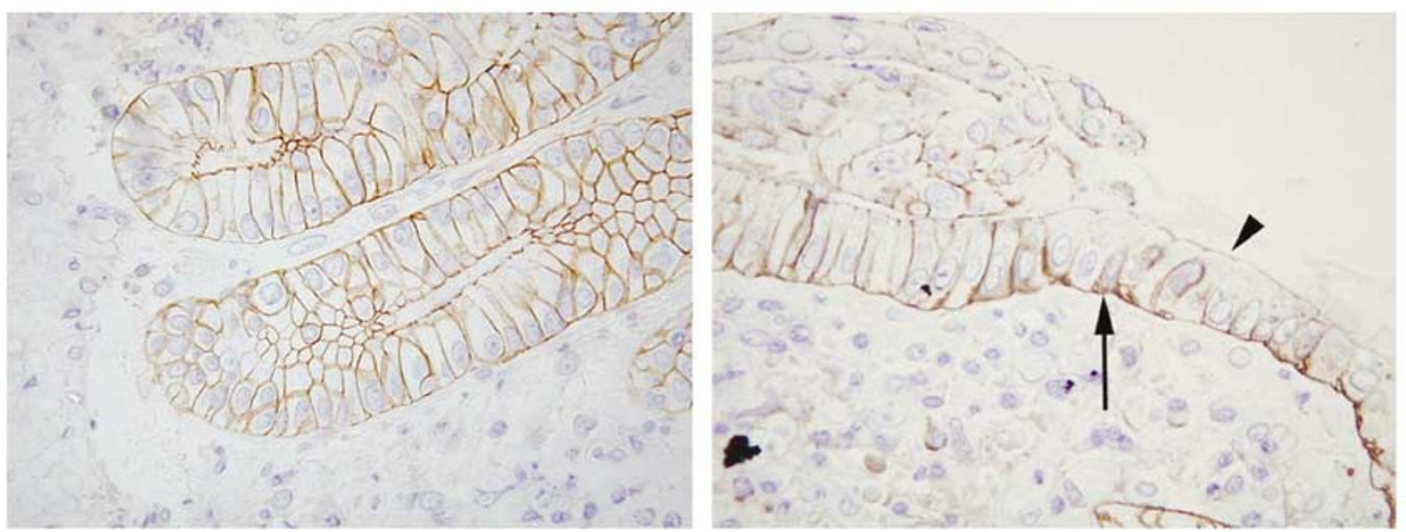

Inactive UC
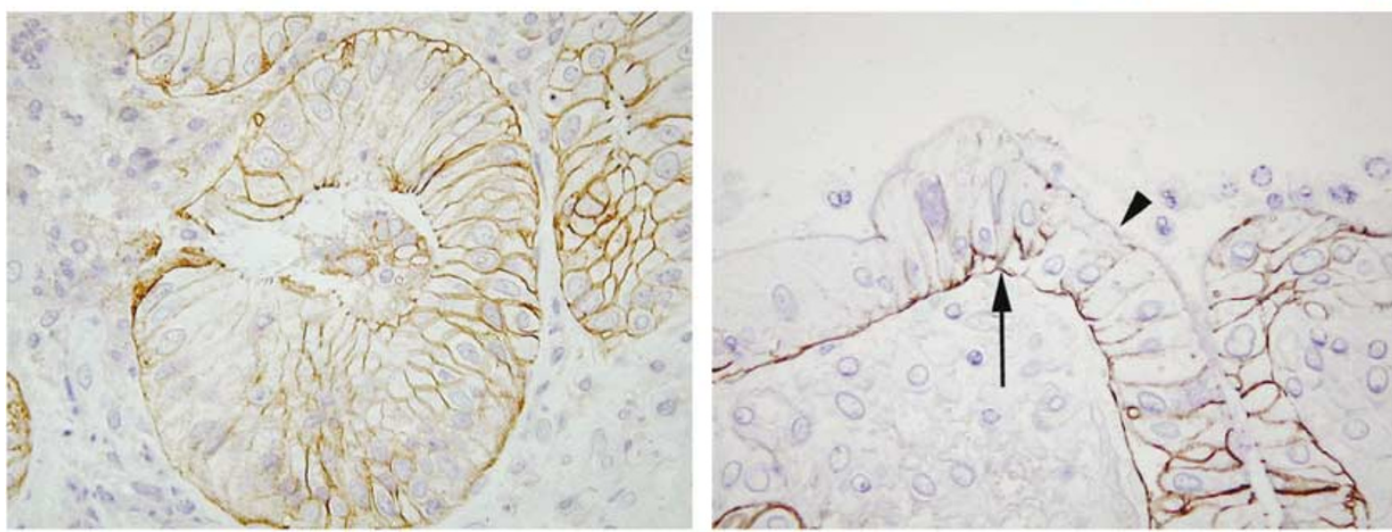

Active UC

Figure 3 Representative photomicrographs of claudin 4 staining in colonic biopsies. Epithelial crypt areas are shown on the left with surface epithelial areas on the right. Claudin 4 staining is strong in normal colonic epithelium with reduced staining in IBD surface epithelium in the tight junction areas, particularly in UC (arrowheads), while staining is retained or increased at the basolateral membranes (arrows). Original magnification $\times 400$. 
cell membranes. In CD and particularly UC, the staining intensity of claudin 3 was reduced only in the surface epithelium, with marked loss from the lateral and junctional membranes of some cells (Figure 2). Surface epithelial cell staining loss reached statistical significance upon further analysis (Table 1). Claudin 4 staining of IBD biopsies was reduced in some areas of the lateral cell membranes and tight junctions in the surface epithelium, most often in UC (Figure 3). The staining sometimes appeared to be redistributed away from the junc- tions to the basolateral region of surface epithelium. Differences in claudin 4 staining were not statistically significant upon extended analysis of the immunohistochemistry (Table 1). All negative antibody controls for claudin staining were negative (data not shown).

Some whole mounts of isolated normal epithelium were stained with ZO-1, prior to use in Western blotting, to assess the integrity of tight junctions after isolation in citrate buffer (Figure 4a). This showed that ZO-1 staining was in a discrete a

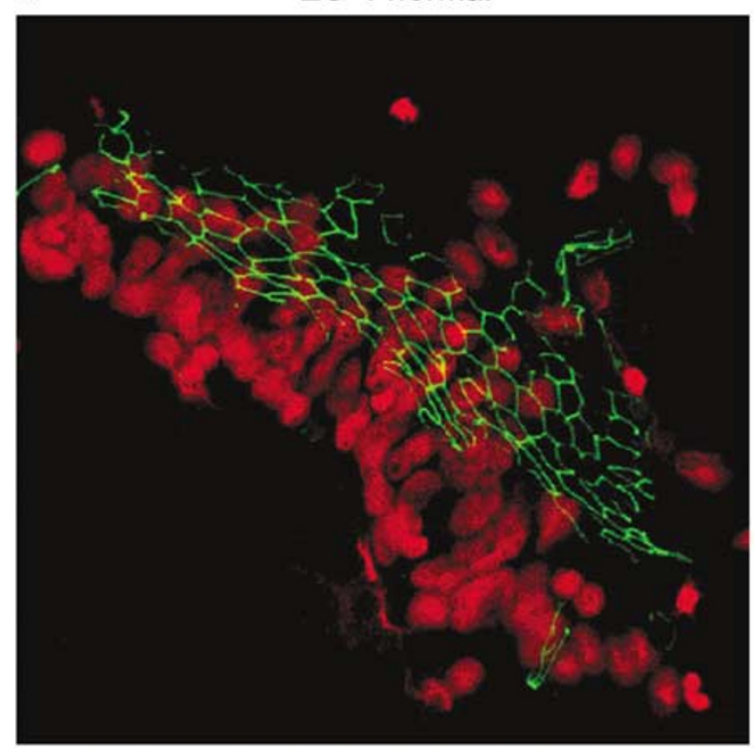

c

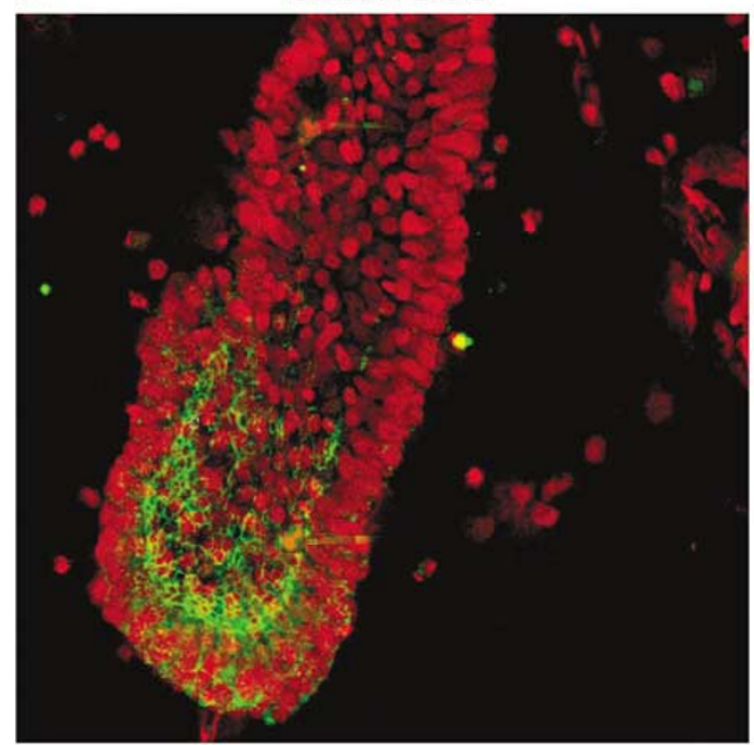

b

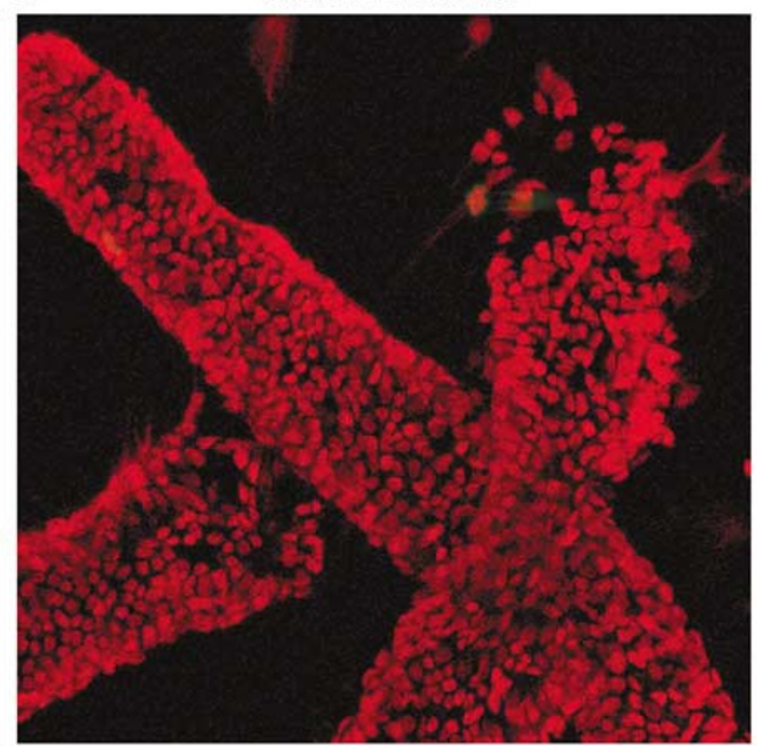

d
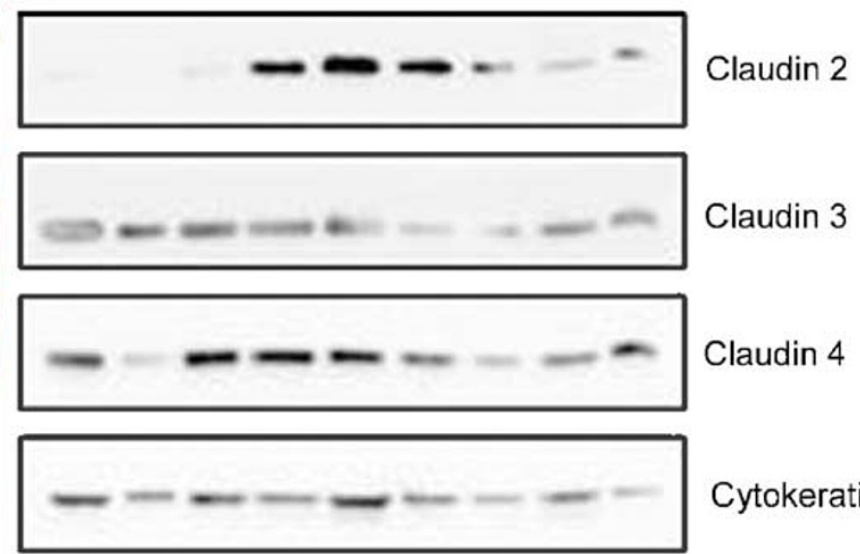

Claudin 4

Cytokeratin 19 
Table 2 Digital quantitation of Western blots of colonic epithelial cells from resected IBD specimens reacted with claudin antibodies

\begin{tabular}{lccc}
\hline Claudin & Normal $(\mathrm{n}=6)$ & $\begin{array}{c}\text { Ulcerative colitis } \\
(\mathrm{n}=6)\end{array}$ & $\begin{array}{c}\text { Crohn's disease } \\
(\mathrm{n}=3)\end{array}$ \\
\hline 2 & $0.02(0.01-0.04)$ & $56(0.5-193)^{*}$ & $1.1(0.4-10.6)^{* *}$ \\
3 & $0.88(0.33-1.89)$ & $0.61(0.09-0.79)$ & $0.68(0.49-2.14)$ \\
4 & $0.7(0.19-2.17$ & $1.00(0.34-3.98)$ & $0.78(0.77-9.51)$
\end{tabular}

The ratio of the density of claudin to cytokeratin 19 immunoreactivity was calculated to normalise for differences in amounts of epithelial proteins that may occur between samples. Results are expressed as median (range).

${ }^{*} \mathrm{UC}$ vs normal, $P=0.004 ;{ }^{*} \mathrm{CD}$ vs normal, $P=0.02$.

junctional location and suggested that there was no junctional disassembly in relation to the use of the citrate isolation buffer (as seen for example in Figure $8 \mathrm{c}$ in response to incubation in $\mathrm{Ca}^{2+}$-free HBSS). Claudin 2 staining of whole mounts showed an absence of staining in the normal tissue (Figure 4b) with strong staining in the crypts from UC (Figure 4c) in the subapical junctional regions of cells that confirmed the claudin 2 upregulation seen in the stained sectioned biopsies (Figure 1) and again that cellular integrity was maintained in these cell preparations. Western blotting of isolated crypt and surface colonic epithelium revealed low or negligible amounts of claudin 2 in normal colon, but markedly increased levels in UC epithelium with modestly increased amounts in CD (Figure 4d, Table 2). There were no significant differences in total claudin 3 or 4 protein on Western blots between normal colon and UC or CD. All antibody controls were negative (data not shown).

\section{The T84 Cell Culture Model Mimics Claudin Expression Found in Human Colonic Epithelium}

By 2 days at confluence, claudins 3 and 4 showed a widespread distribution across the monolayer with both cytoplasmic and basolateral membrane staining (Figure 5a). Large areas of claudin 2 positive cells were also seen, interspersed with small regions of negative cells. In positive cells, claudin 2 was distributed in a distinct pattern, characteristic of incorporation into the TJ, and much less cytoplasmic and extrajunctional staining was seen than with claudins 3 and 4 . By day 8 , claudins 3 and 4 were seen in a junctional pattern with loss of most cytoplasmic staining: however, the number of cells positive for claudin 2 had dropped dramatically, such that only occasional small clusters of positive cells were seen. XZ views of the staining reflected the reduction in claudin 2 staining and junctional assembly of claudins 3 and 4 (Figure $5 d$ ). A similar pattern of staining was seen on day 15 . Western blots revealed strong immunoreactivity of claudin 2 at day 2, with lower expression at later time points, while claudin 3 increased and claudin 4 remained similar with time (Figure 5c). Between day 2 and 15 the TER increased steadily from less than $100 \Omega \mathrm{cm}^{2}$ to more than $600 \Omega \mathrm{cm}^{2}$ (Figure 5b).

\section{IL-13 and TNF $\alpha / \mathrm{IFN} \gamma$ have Differential Effects on Claudin Expression and Epithelial Barrier}

We next examined whether inflammatory cytokines known to be upregulated in IBD mucosa affect barrier function ${ }^{49}$ and claudin expression. At 3 days incubation of 15 day monolayers with IFN $\gamma / \mathrm{TNF} \alpha$ led to further decreases in the number of cells staining positive for claudin 2 (Figure 6a) and reduced protein expression by Western blotting (Figure 6b). There was also a reduction in claudin 3 staining at junctions (Figure 6a) and loss of claudin 4 from junctional areas with increases in cytoplasmic immunofluorescence that is strikingly evident in the XZ inset micrograph in Figure 6a. Western blotting showed no change in total claudin 3 and 4 (Figure $6 \mathrm{~b}$ ). TNF $\alpha$ and IFN $\gamma$ induced a fall in TER relative to control monolayers of $52 \%$ (Figure 6d), and a four-fold rise in FITCdextran passage (Figure 6c). Exposure to 3 days of IL-13, however, led to a marked increase in claudin 2 expression, with most of the claudin 2 staining observed in the subapical membrane in a tight junction pattern (Figure 7a and XZ inset). Western blotting confirmed this increase (Figure 7b). There were no changes in the immunofluorescent expression patterns (Figure 7a) or Western blots (Figure 7b) for claudin 3 or 4 . IL-13 exposure led to a $72 \%$ fall in the TER relative to control monolayers (Figure $7 \mathrm{~d}$ ) and a 2.5-fold increase in FITC-dextran passage (Figure 7c).

\section{Expression of Claudin 2 in an Intact Epithelial Barrier} does not Correlate with Cell Division

The lower part of the crypt is the site of the transit amplifying zone of dividing enterocytes, ${ }^{50,51}$ which is expanded in IBD. ${ }^{52,53}$ It is a possibility that increased proliferation rates in IBD promote increased plasticity at cell-cell contacts and change the regulation of tight junction claudin 2 expression. In 7-day confluent T84-cell monolayers, many proliferating cells were seen, dispersed among cells out of cycle, using the cell cycle marker Ki 67, whereas claudin 2 was expressed in small clusters of cells (Figures 8a and b). Dual staining showed no correlation between the cells that were positive for claudin 2 and Ki67 (Figures 8a and b) suggesting that there was no clear relationship between cell division and claudin 2 expression and that the cell culture model mimicked the normal colon in this respect. 
Reassembly of Tight Junctions by Extracellular Ca2 ${ }^{+}$ Replacement does not Increase Claudin 2 Detection

Claudin 2 appeared to be incorporated into the TJ in the early stages of barrier formation. We therefore examined whether disassembling the TJs in a confluent day 7 monolayer, by reducing the extracellular calcium ion $\left(\mathrm{Ca}^{2+}\right)$ concentration, would lead to an increase in claudin 2 expression upon $\mathrm{Ca}^{2+}$ replacement and junctional reassembly. Two hours of $\mathrm{Ca}^{2+}$ withdrawal led to a complete disruption of the characteristic patterns of staining seen in control cells (Figure 8c). ZO-1 was seen as large aggregates of discontinuous staining and claudin 2 also appeared to be dissociated from cell junctions with bright spots of membrane staining and increased cytoplasmic staining. Replenishment of normal extracellular $\mathrm{Ca}^{2}+$ led to a restoration of the junctional pattern of ZO-1 staining at $24 \mathrm{~h}$. However, there was no evidence of an increase in claudin 2 expression or assembly in the monolayer (Figure 8c). a
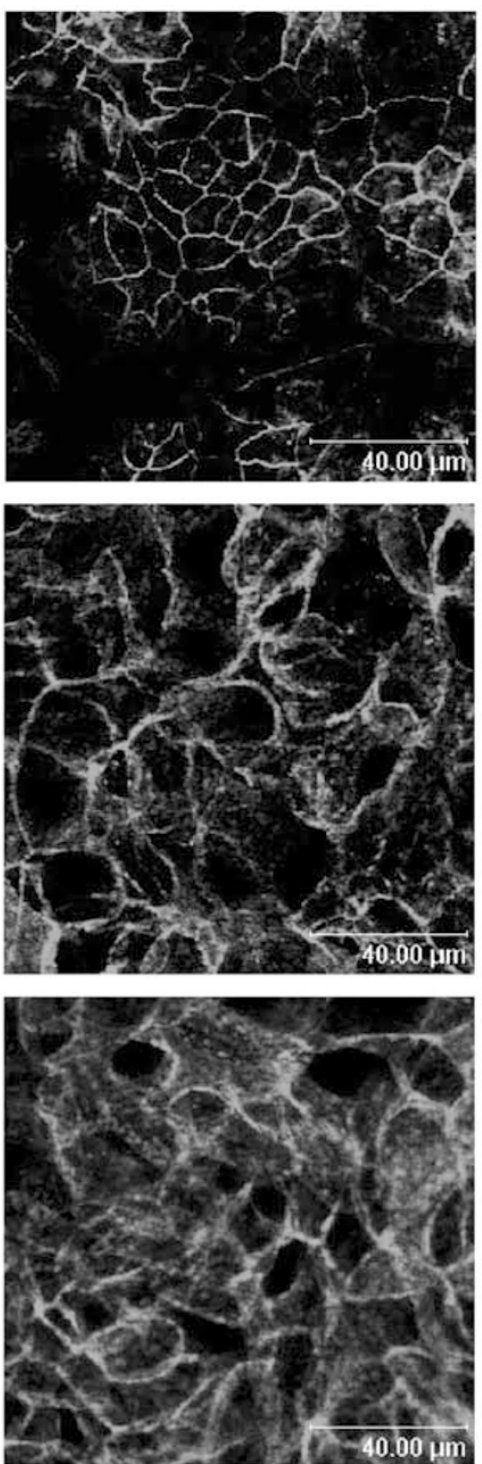

Day 2
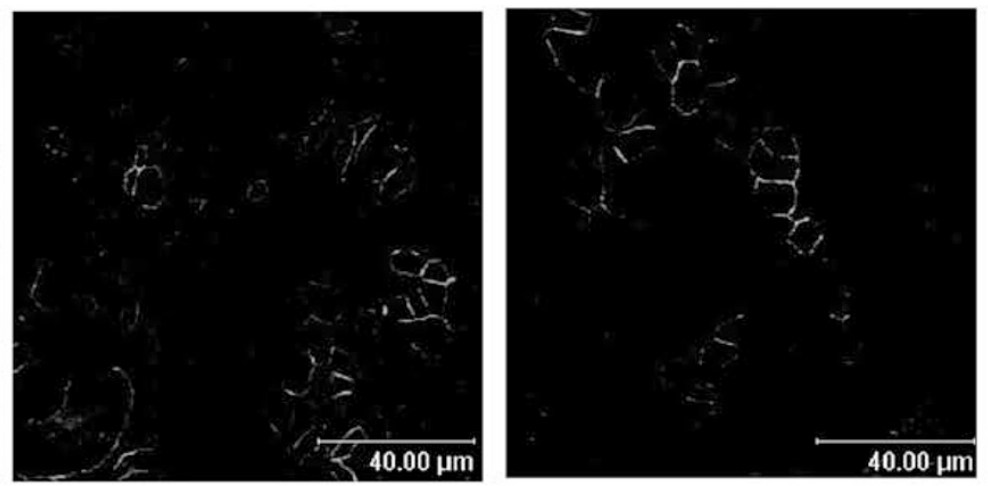

Claudin 2
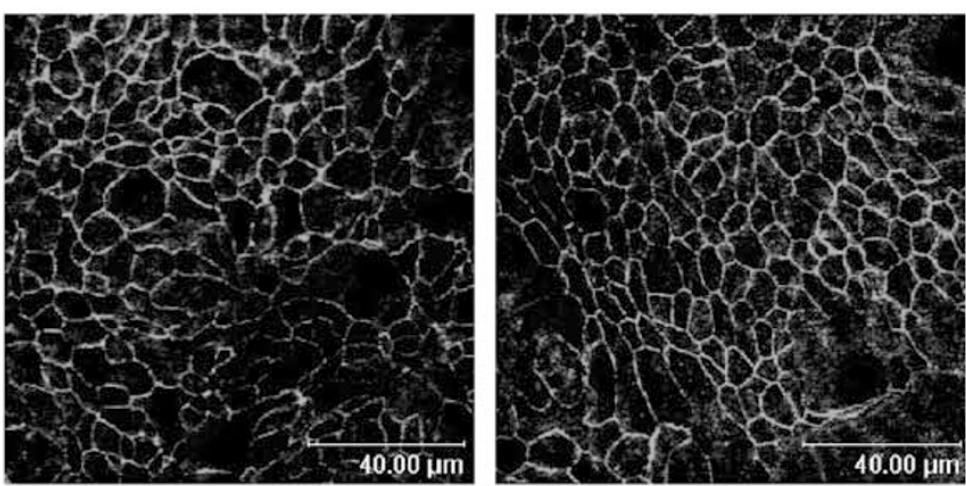

Claudin 3

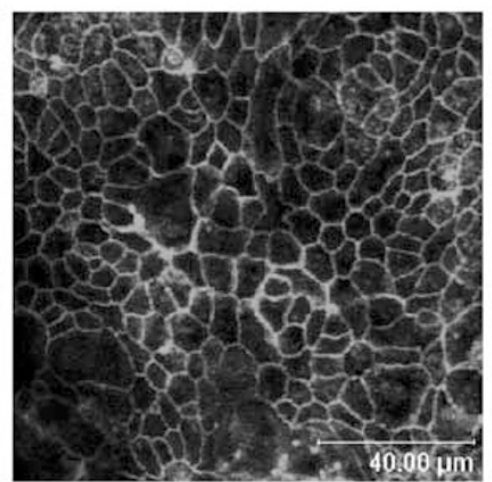

Day 8

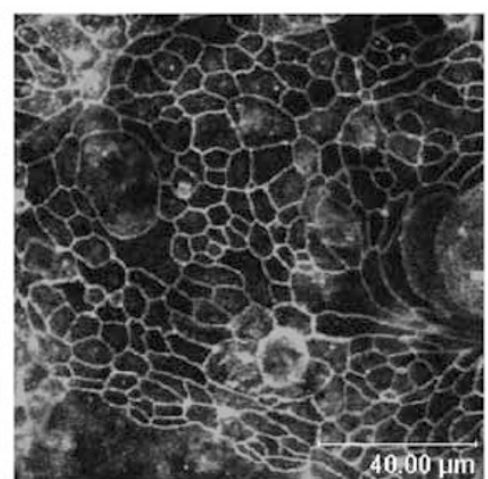

Day 15

Figure 5 Claudin expression and TER subsequent to plating at conluence of T84 monolayers. (a) Confocal micrographs showing immunofluorescent staining of claudins 2, 3 and 4. On day 2, claudin 2 staining is widely expressed across the monolayer, reducing to small clusters of junctional staining on days 8 and 15, which is confirmed in the XZ views shown in (d). Claudin 3 and 4 staining is seen in membrane and punctuate cytoplasmic areas at day 2, changing to a tight junction apicolateral membrane pattern with reduction of cytoplasmic staining at days 8 and 15. These patterns of staining are reflected in the XZ views where both claudin 3 and 4 staining are seen in the lateral membranes at day 2, becoming more discretely localised in a tight junction location at days 8 and 15 (b) TER shows a gradual increase over time following cell plating. (c) Western blotting of claudins 2, 3, 4 and cytokeratin 19, in lysates of total cellular protein at days 2, 8 and 15 after plating of cells, shows a marked decrease in claudin 2, an increase in claudin 3 and little change in claudin 4 with time. 
C
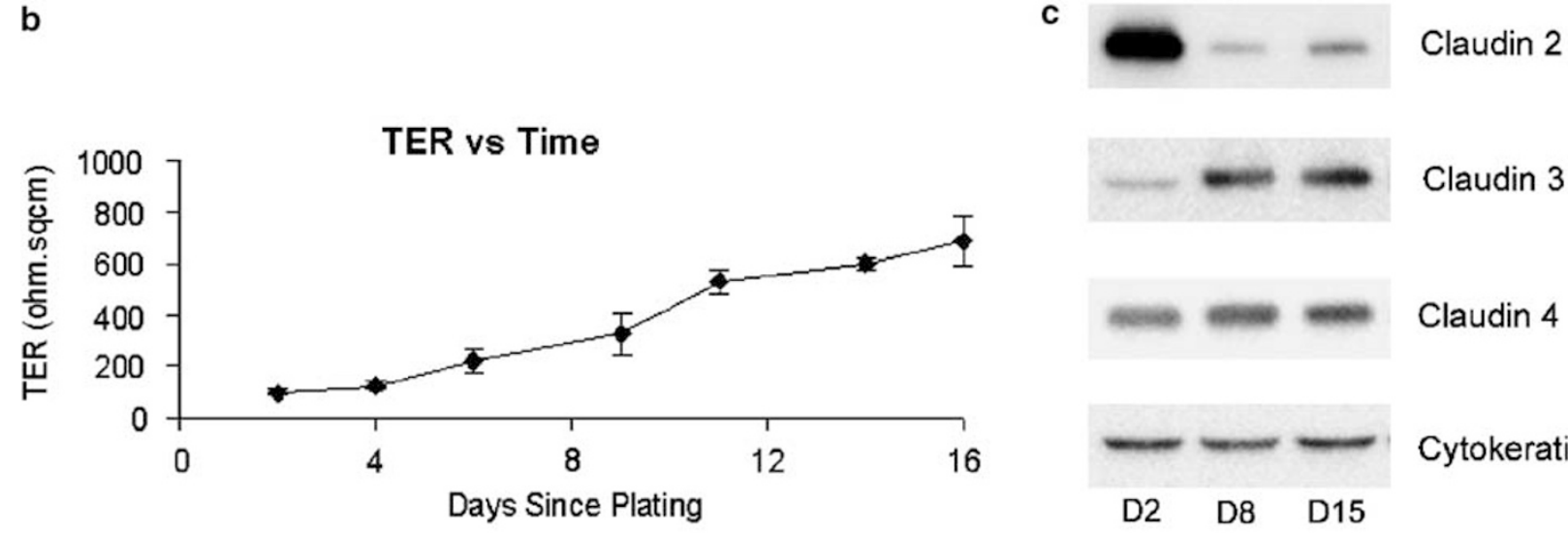
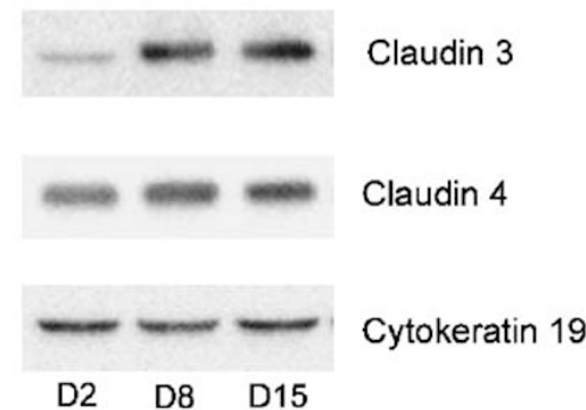

D2 D8 D15 d
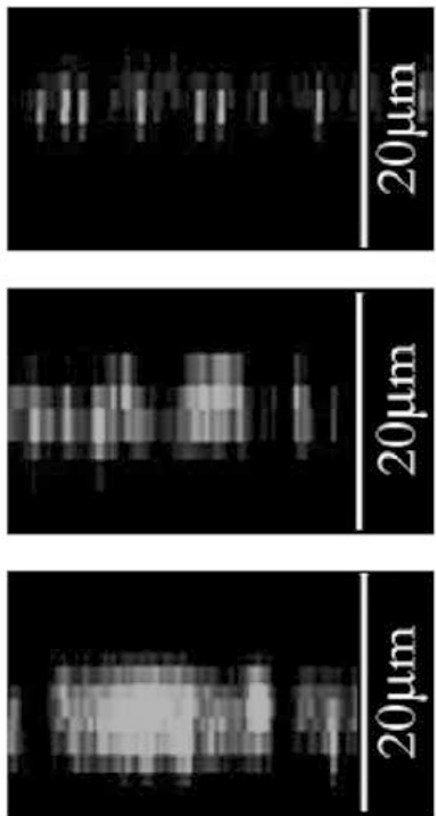

Day 2
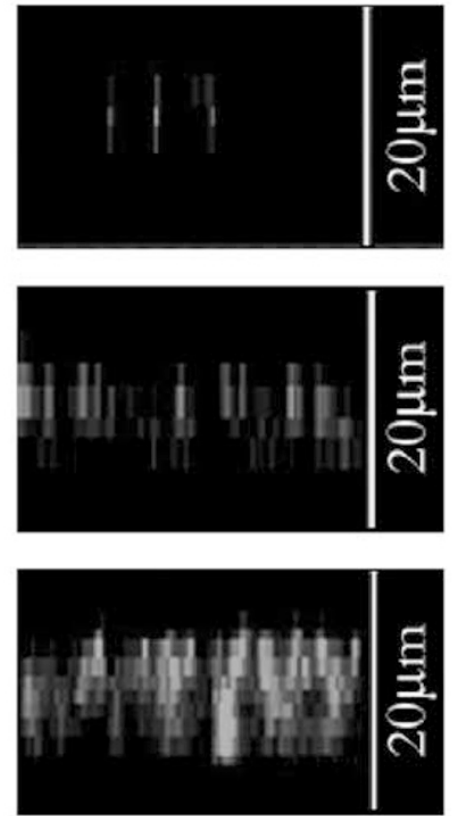

Day 8
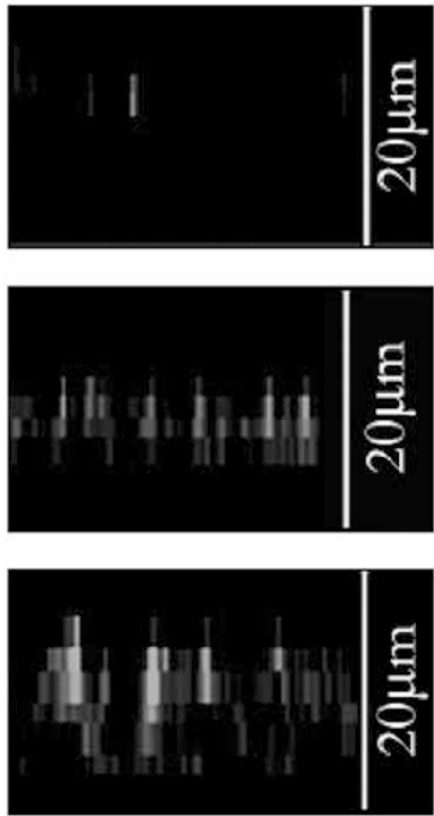

Day 15
Claudin 2

Claudin 3

Claudin 4

Figure 5 Continued.

The P13-Kinase Inhibitor LY294002 Blocks IL-13 Induced Increase in Claudin 2 in T84 Cells

IL-13 is known to activate several intracellular signalling pathways, including the STAT6 pathway $^{54}$ and the PI3-kinase pathway via recruitment of the insulin receptor substrate family. ${ }^{55,56}$ Previous evidence suggested that the reduction in TER across T84 cells induced by IL-13 is mediated by the PI3kinase rather than the STAT6 pathway. ${ }^{57}$ We therefore studied the effects of an inhibitor of PI3-kinase, LY294002, on the IL-13-induced increase in claudin 2 expression and impairment of barrier function. As before, 3 days of IL-13 exposure induced an increase in claudin 2 expression in T84 monolayers. Coincubation with IL-13 and LY294002 impaired the claudin 2 increase in a dose-dependent manner (Figure 9a and b) that was apparent at lower inhibitor doses on the blots (Figure 9b) than with immunohistochemical staining (Figure 9a). However, LY294002 partially, but significantly, restored the TER towards control levels (Figure 9d) and the magnitude of these effects correlated most closely with the immunostaining of junctional proteins rather than total cellular proteins measured on blots. Interestingly, Ly294002 had no effect on the IL-13induced increase in FITC-dextran permeability (Figure 9c). LDH release assays were performed to exclude toxic effects of the treatments (data not shown). Since the TER increased in the LY294002treated cells, this also suggested that the effects of LY294002 were not influenced by toxicity.

To confirm that LY294002 was inhibiting PI3K in T84 cells, monolayers were pre-exposed to either control medium or inhibitors (at different concentrations) for $10 \mathrm{~min}$ and then exposed to control medium or IL-13 for a further $10 \mathrm{~min}$, before being lysed. Incubations (10 min) were carried out as this 
a
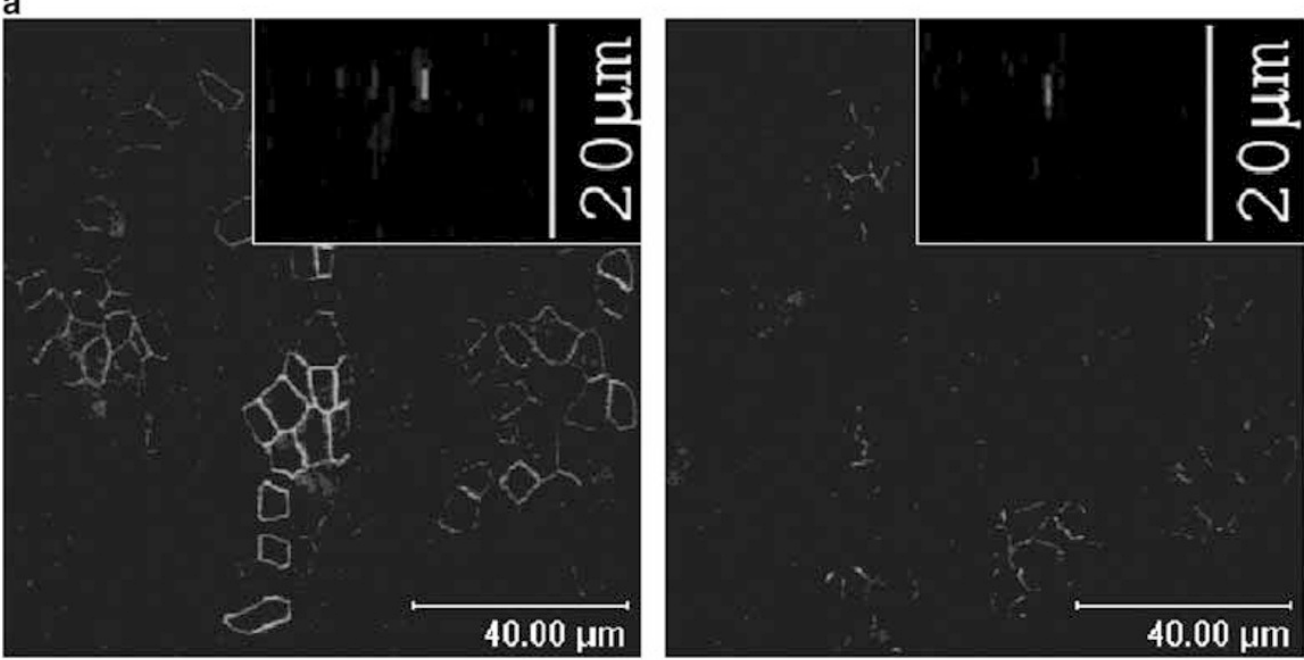

Claudin 2

Claudin 3

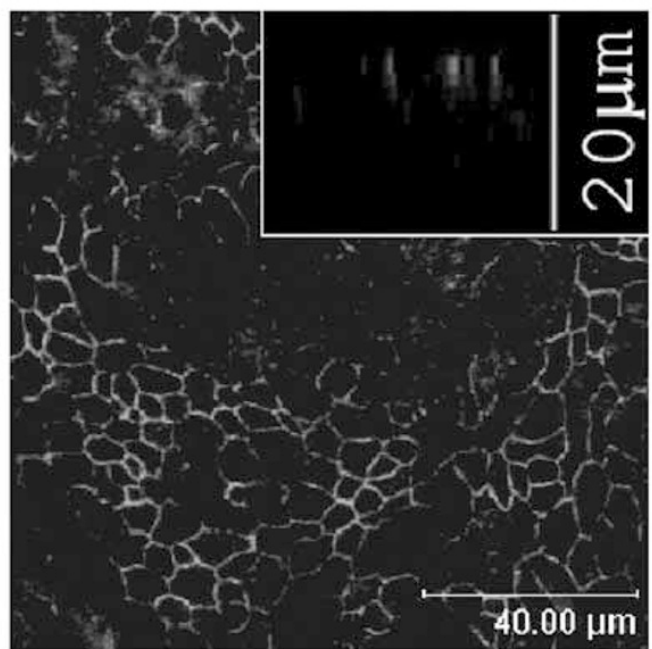

Claudin 4

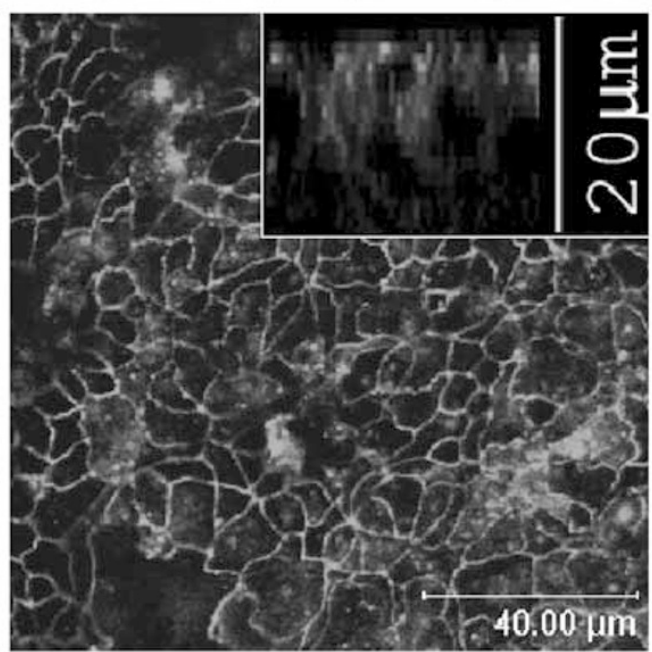

IFN $\gamma+\mathrm{TNF} \alpha$

Figure 6 The effects of exposure of 15-day T84-cell monolayers for 3 days to IFN $\gamma(100 \mathrm{ng} / \mathrm{ml})$ and TNF $\alpha(1 \mathrm{ng} / \mathrm{ml})$ on the expression of claudins 2, 3 and 4. (a) Confocal micrographs of immunofluorescent staining at day 0 (left-hand panel) and after day 3 (right-hand panel) of cytokine treatment showing reduced staining of claudins 2 and 3, with claudin 4 showing loss of cell border staining, appearance of punctate cytoplasmic aggregates and increased basolateral staining (XZ views in insets). (b) Western blotting of whole cellular protein lysates shows a marked reduction in claudin 2 induced by IFN $\gamma / \mathrm{TNF} \alpha$, with no change in claudins 3 and 4 . (c) Increase in the permeability to FITC-labelled $4 \mathrm{kDa}$ dextran in response to IFN $\gamma / \mathrm{TNF} \alpha$ and (d) reduction in TER after cytokines. The mean starting TER in controls was $770.4 \Omega \mathrm{cms}^{2}$ with SEM 54.1 ( $n=6$ filters) and in the TNF $\alpha /$ IFN $\gamma$ cohort $767.4 \mathrm{cms}^{2}$ with SEM 107.4 ( $n=6$ filters) (Contcontrol monolayers; ${ }^{+} P<0.05$ for the increase in FITC-dextran passage and ${ }^{*} P<0.0001$ for the TER, $n=6$ ). 
b

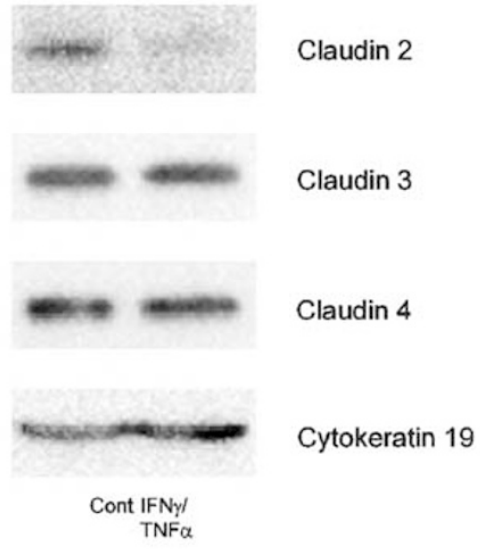

C
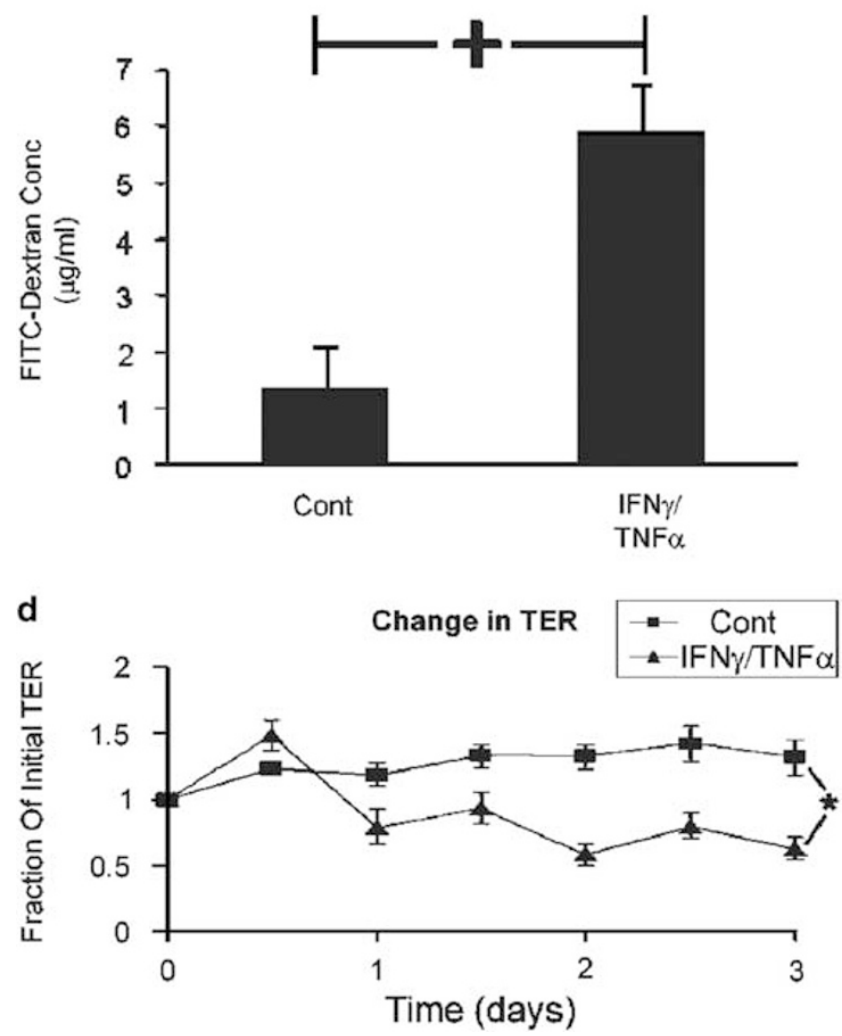

Figure 6 Continued.

time-frame is often used to monitor these types of cell membrane signalling events. ${ }^{58}$ PI3-kinase activates Akt/protein kinase $\mathrm{B}$ by phosphorylating serine $473,{ }^{59}$ so we used phospho-Akt ser 473 antibody on Western blots and compared it to total Akt using a second antibody on the same stripped blots. Phospho-Akt was increased above background after $10 \mathrm{~min}$ exposure to IL-13, and LY294002 significantly reduced phosphorylation of Akt to control levels or below (Figure 9e) confirming the efficacy of the inhibitor. Total Akt expression was not significantly altered after $10 \mathrm{~min}$ of IL-13 exposure, with or without inhibitors (Figure 9e).
The Kinetics of Phospho-Akt Activation Correlates with the Timing of Claudin 2 Expression

In order to study the kinetics of the T84-cell responses to IL-13 in more detail, cell monolayers were stimulated with IL-13 or lithium chloride, a known activator of p-Akt via PI3K, ${ }^{60}$ this time in the absence of serum and insulin in order to remove other sources of exogenous stimulation of PI3K ${ }^{61}$ and allow us to see the specific effect of IL-13 and LiCl on PI3K. Both treatments induced strong expression of claudin 2 at $12 \mathrm{~h}$ of incubation, which was preceded by upregulation of p-Akt with similar, though not identical, kinetics (Figure 10a and b) consistent with a role for $\mathrm{p}$-Akt in the induction of claudin 2 expression. Immunofluorescent antibody studies showed areas of claudin 2 positive cells, with circumferential staining, at $12 \mathrm{~h}$, increasing in number at $24 \mathrm{~h}$ in both IL-13 and LiCl-treated cultures (data not shown).

\section{Relative Numbers of Claudin 2 Transcripts are Increased in IL-13-Treated T84-Cell Monolayers}

IL-13 stimulated a four-fold increase in mRNA transcripts in T84-cell monolayers previously incubated for $16 \mathrm{~h}$ in serum and insulin-free medium. This relative rise in transcript number was inhibited and further suppressed by Ly294002 to below control values (Table 3). Similar results were obtained in the presence of serum (data not shown).

\section{Relative Numbers of Claudin 2 Transcripts are Increased in Colonic IBD Epithelium}

Relative quantitation of reverse transcriptasemediated PCR showed that in IBD tissues, there was an increase in claudin 2 transcripts, compared with normal, (IBD vs normal, $P=0.004$ ). This was statistically significant in UCvs normal $(P=0.012)$ though not in $\mathrm{CD}(P=0.22)$ due to wider variation in the $C_{\mathrm{T}}$ values of the latter (Table 4 ).

\section{Discussion}

We show here that the expression of claudin 2 protein and mRNA is significantly raised in the colonic epithelium in both CD and UC. This is in contrast to claudin 3 and 4 proteins that are only sporadically reduced or redistributed compared to normal colonic epithelia. Our study confirmed that claudins 2, 3 and 4 are expressed in human colon in agreement with Burgel et $a l^{28}$ who showed that claudin 2 expression was increased and claudin 4 was decreased in collagenous colitis, an inflammatory condition of unknown aetiology. Taken together these observations could help to explain the increased ion flux and diarrhoea in IBD. An emerging view of claudins is that they have fixed charges on their extracellular loops, lining aqueous pores in 

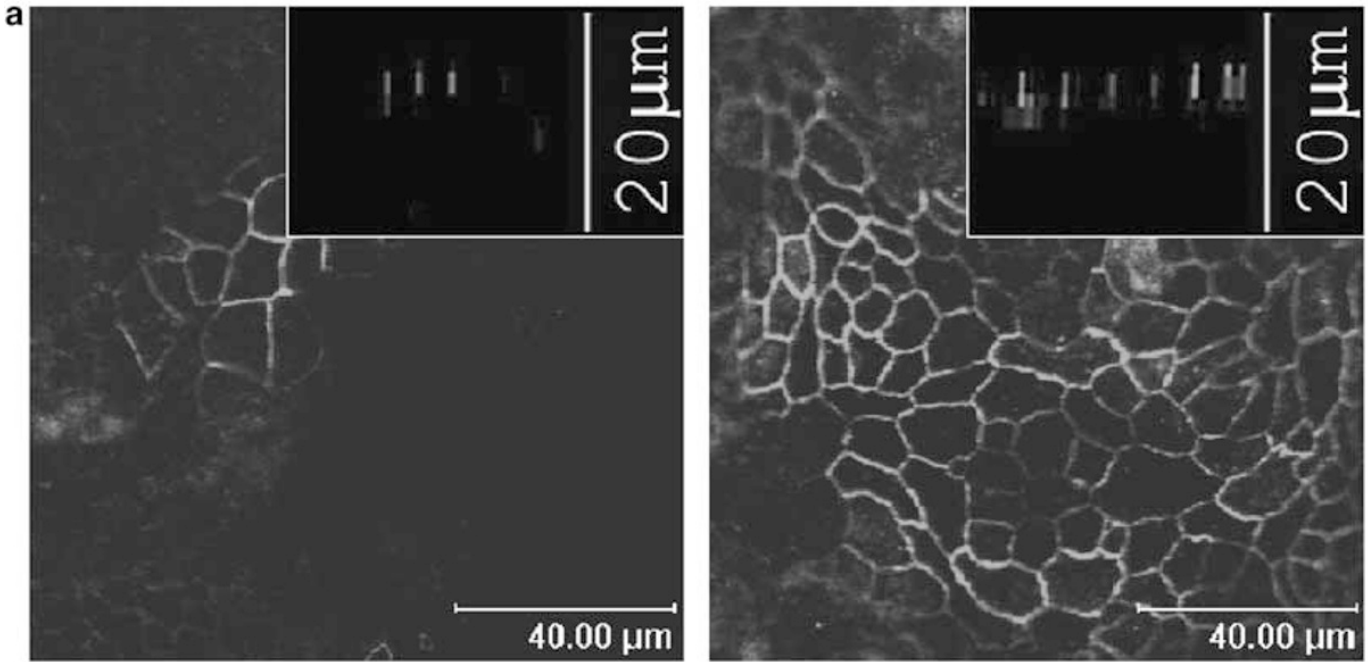

Claudin 2
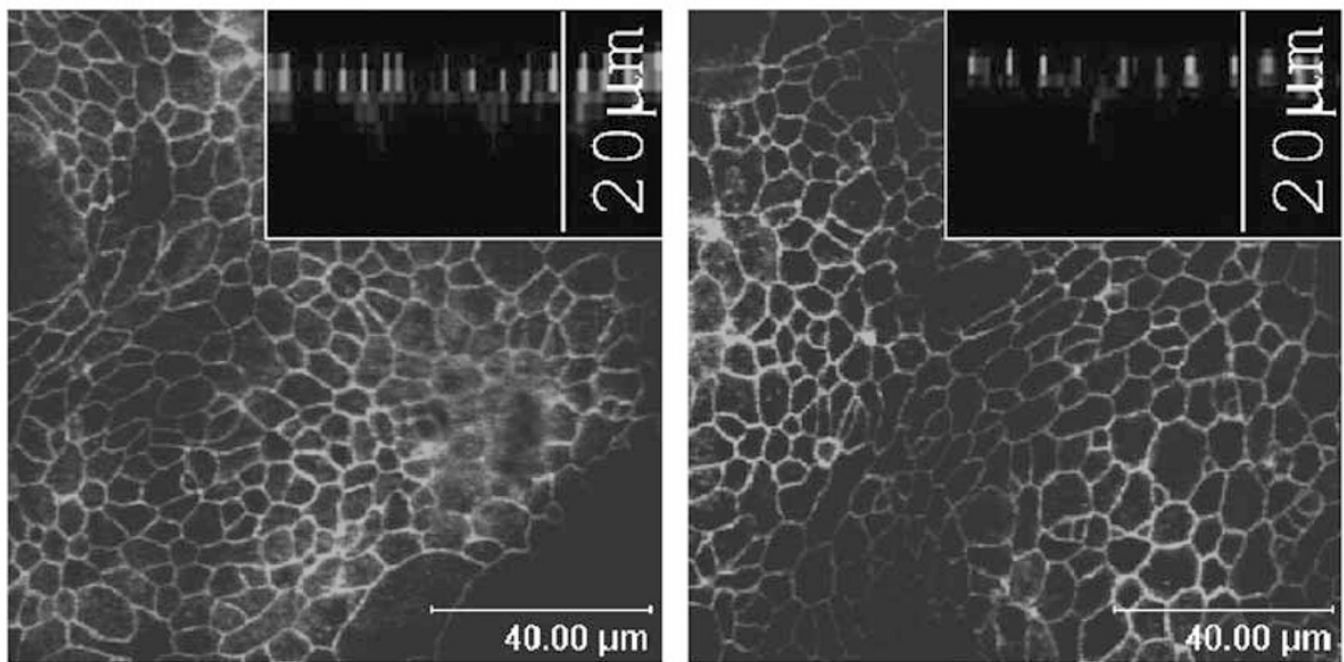

Claudin 3

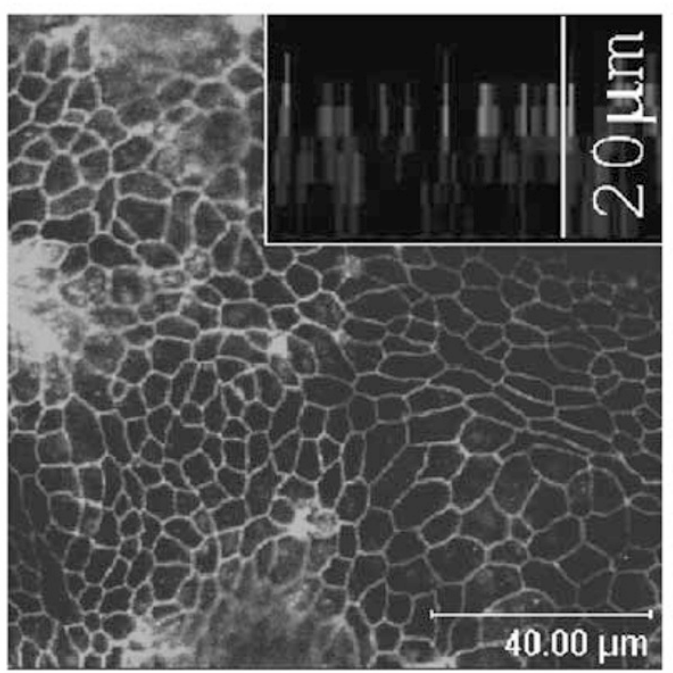

Control

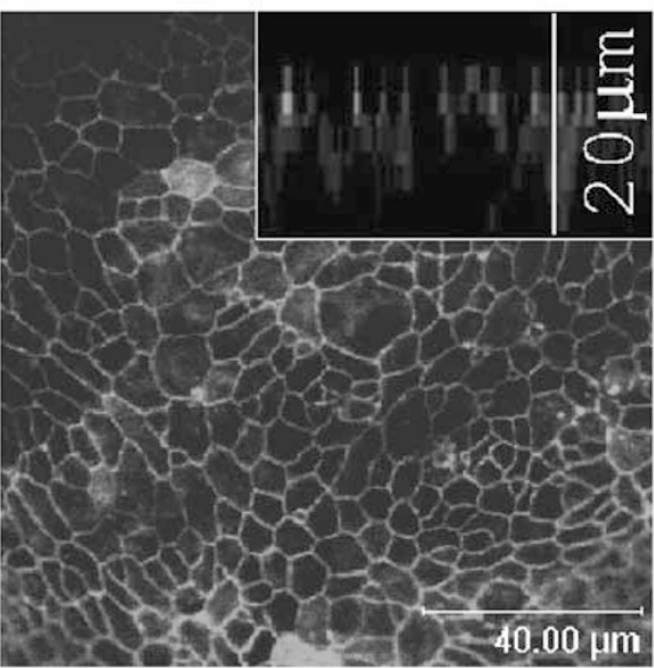

IL-13
Claudin 4

Figure 7 The effects of exposure of a 15-day T84-cell monolayer to IL-13 (2 ng/ml) for 3 days on the expression of claudins 2 , 3 and 4 . (a) Confocal micrographs of immunofluorescent staining at day 0 (left-hand panel) and day 3 (right-hand panel) of cytokine treatment show a dramatic increase in claudin 2, while claudins 3 and 4 staining remains unchanged. The XZ views in insets confirm the interpretation of the staining data. (b) Western blotting of whole cellular protein lysates shows increased detection of claudin 2 and no change in claudins 3 and 4. (c) Increase in the permeability to FITC-labelled $4 \mathrm{kDa}$ dextran and (d) reduction in TER after cytokine exposure. The mean starting TER in controls was $594.2 \Omega \mathrm{cms}^{2}$ with s.e.m. $61.4\left(n=6\right.$ filters) and in the IL-13 cohort $613.5 \Omega \mathrm{cms} \mathrm{s}^{2}$ with s.e.m. $30.8(n=6$ filters) (Cont-control monolayers; ${ }^{+} P<0.05$ for the increase in FITC-dextran passage; ${ }^{*} P<0.0001$ of TER, $n=6$ ). 
b
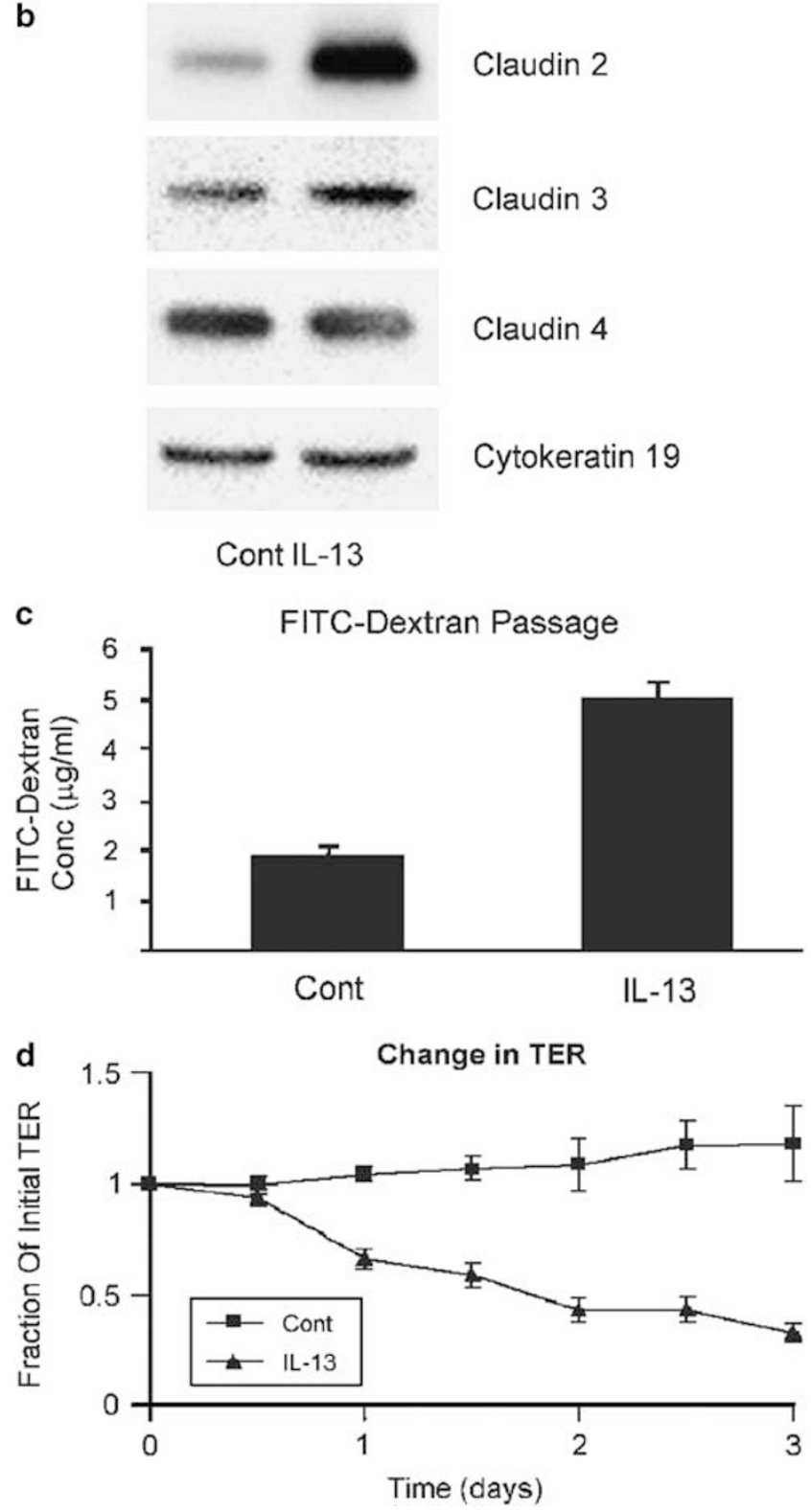

Figure 7 Continued.

tight junctions that electrostatically influence the passage of soluble ions. ${ }^{62}$ Claudin 2 , which appears in a tight junction location throughout the extended crypts of disease specimens, has been shown to induce cation-selective channels in the tight junctions of 'tight' epithelia resulting in increased paracellular permeability to sodium. ${ }^{63,64}$ The localisation of claudin 3 was also affected in disease specimens, where the staining intensity was reduced in the surface epithelium, with marked loss from the lateral and junctional membranes of some cells. This is interesting because overexpression of claudin 3 , in a cell culture barrier model, had no apparent effect on TER. ${ }^{63}$ However, the phosphorylation of threonine 192 in claudin 3 has recently been shown to cause barrier defects and a reduction in the amount of staining for claudin 3 in the tight junctions of cultured ovarian cancer cells ${ }^{65}$ implicating altered regulation of claudin 3 as a potentially important regulator of epithelial barrier permeability. While claudin 4 expression was similar to normal on Western blots of diseased epithelial cells, its localisation was often found to be extrajunctional and basolateral in immunohistochemical studies of disease specimens, suggesting that a redistribution of protein away from the junctional regions had occurred, potentially contributing to decreased paracellular permeability in the epithelium. Claudin 4 overexpression has been shown to decrease permeability to sodium ${ }^{66,67}$ and when the extracellular domains of claudin 4 were substituted for the extracellular domains of claudin 2 in MDCK cells, permeability to sodium was decreased significantly relative to chloride and the TER increased several fold ${ }^{68}$ Increased permeability may have a protective function in the gut, in acute responses to infection. For example, increased permeability may contribute to the expulsion of parasitic nematodes where IL-13 is important for protective immunity. ${ }^{69}$ In any event, raised claudin 2 might become detrimental in chronic inflammation.

In IBD tissues, positive claudin 2 staining coincided predominantly with the dividing cells in the hyperplastic crypts. Increased rates of cell division and cell movement/shedding have been reported in $\mathrm{IBD}^{52,53}$ prompting speculation that the increased expression of claudin 2 might be related to cell division or increased plasticity of tight junctions in disease. However, a recent study of fetal human colon, at 18-20 weeks gestation, revealed claudin 2 staining in the undifferentiated cells at the bases of developing colonic crypts with loss of staining as the cells differentiate, suggesting that the loss of expression of claudin 2 in normal tissue may relate to differentiation. ${ }^{70}$

The 2-day confluent T84-cell culture model of the epithelial barrier strongly expressed claudin 2 staining in a junctional pattern with less wellorganised expression of claudins 3 and 4. In 8-day monolayers, where claudin 2 was absent or sporadically expressed and claudins 3 and 4 strongly expressed in a tight junction location, this correlated with increased TER and was found to mimic the expression characteristics of claudins seen in normal colon. We found no evidence of correlation between cell division or junctional disassembly/ reassembly and claudin 2 expression in cell cultures sporadically expressing claudin 2 . Recent studies in Caco-2 cells showed expression of claudin 2 throughout confluent monolayers, early after plating, with downregulation during subsequent differentiation, ${ }^{70}$ consistent with the T84 model studied here, again implicating differentiation as a better correlate of claudin 2 expression than cell division.

The expression characteristics of claudins 2,3 and 4 in the T84 monolayer allowed us to test functional responses to inflammatory cytokines 

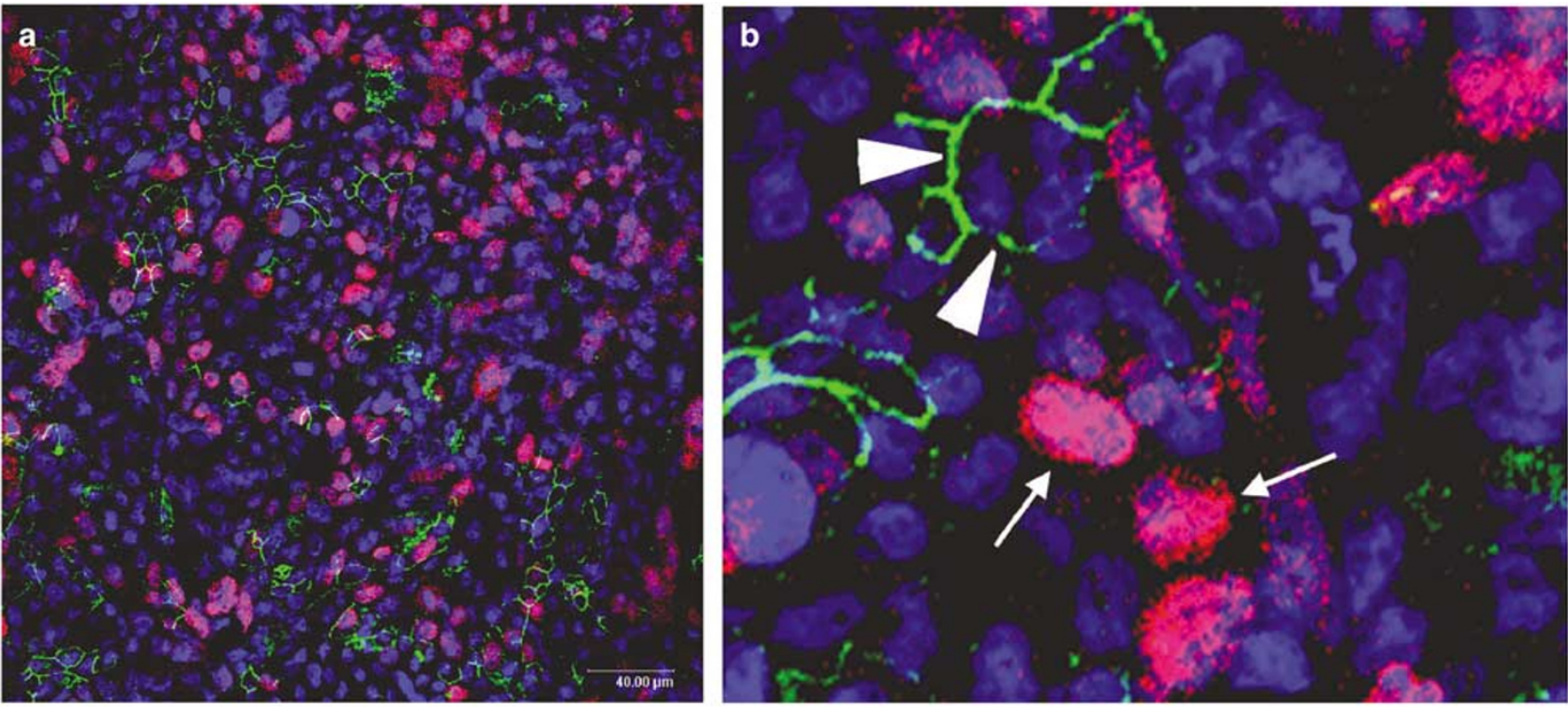

C
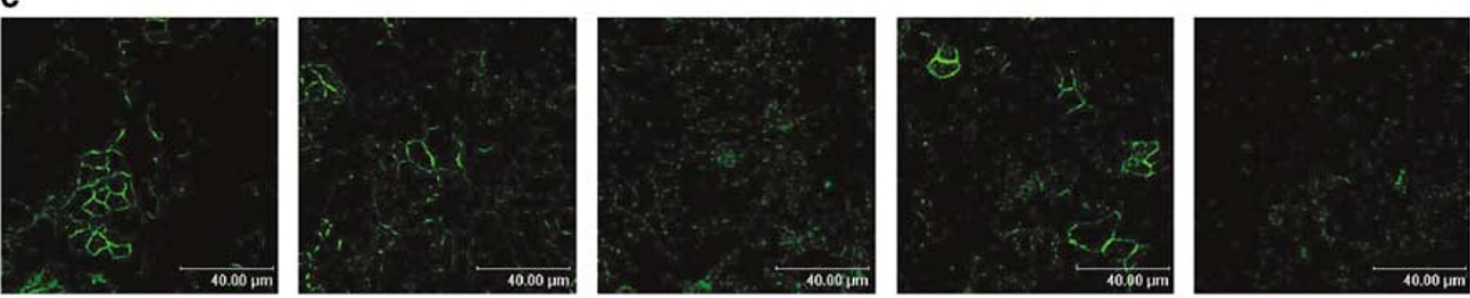

Claudin 2

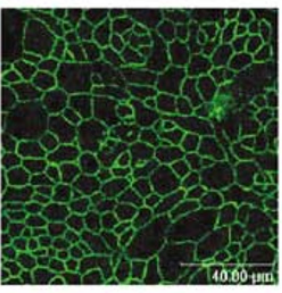

0 hrs

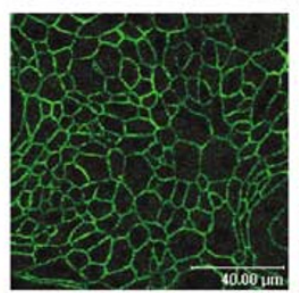

Control

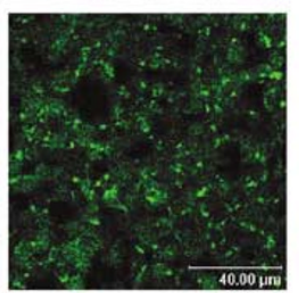

Ca-free

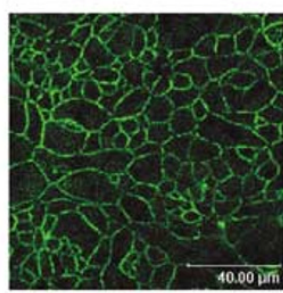

Control

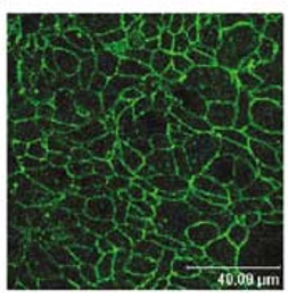

Ca replaced

2 hrs

24 hrs

Figure 8 Confocal micrographs of 7-day T84 monolayers with dual immunofluorescent staining with antibodies to claudin 2 and Ki67 (top panels) and the effects of $\mathrm{Ca}^{2+}$ withdrawal and replacement on claudin 2 and ZO-1 expression (bottom panels). Panels (a) and (b) show no specific cellular colocalisation of claudin 2 staining in green (arrowheads) and Ki 67 staining in red (arrows). Nuclei are counterstained with TOPRO-3-iodide (blue). (c). Confocal micrographs of immunofluorescent staining are a day $7 \mathrm{monolayer}$ at $0 \mathrm{~h}(0 \mathrm{~h})$, after incubation in HBSS for $2 \mathrm{~h}$ with (control) or without $\mathrm{Ca}^{2+}\left(\mathrm{Ca}^{2+}\right.$-free). There is loss of junctional membrane staining of both claudin 2 and ZO-1 in $\mathrm{Ca}^{2+}$-free, which appear as discontinuous membrane-associated spots with increased cytoplasmic staining. After a further $24 \mathrm{~h}$ incubation of the control or $\mathrm{Ca}^{2+}$-free monolayers in normal medium (control and Ca-replaced, respectively), the previous patterns are restored, without a noticeable increase in the expression of claudin 2 in the monolayer.

reported to be expressed in IBD and using this model system ${ }^{29,39,40,71}$ we have studied the TER responses to inflammatory cytokines that are reproducibly changed relative to controls, although they may not be identical to those in vivo. ${ }^{72}$ In addition, although it cannot be entirely excluded that altered secretion mechanisms could contribute to changes in the TER in response to cytokine treatments, Madara and Stafford, ${ }^{29}$ showed that INF $\gamma$ treatment, analysed by ${ }^{22} \mathrm{Na}$ and ${ }^{3} \mathrm{Hmannitol}$ dual flux techniques, led to an effect that was attributable to changes in tight junction permeability.
TNF $\alpha /$ IFN $\gamma$ combined, and IL-13 alone caused a drop in permeability with a decrease in the TER and increases in the passage of uncharged dextran, however only IL-13 produced an increase in claudin 2 expression. These data indicate that there are differences in the molecular basis of the cellular responses producing the permeability changes with respective cytokine treatments. IL-13 has been shown to increase ion and solute permeability ${ }^{57,73,74}$ but claudins have not been studied in this context. In our study, IL-13 treatment of T84 monolayers produced no observed change in claudins 3 and 4 
a

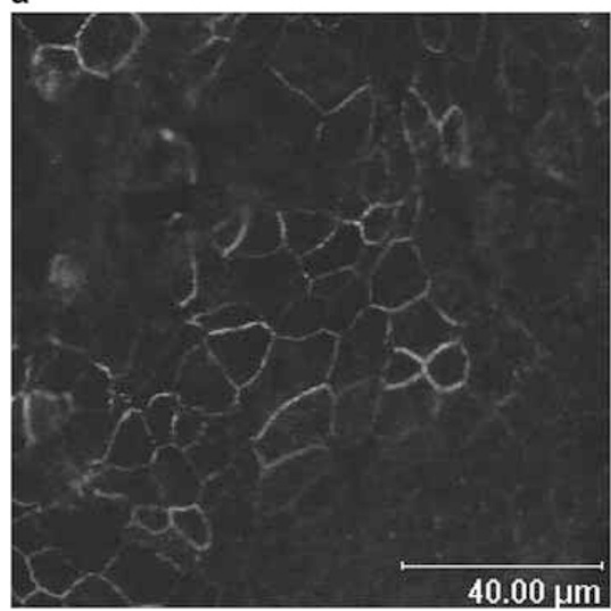

Control

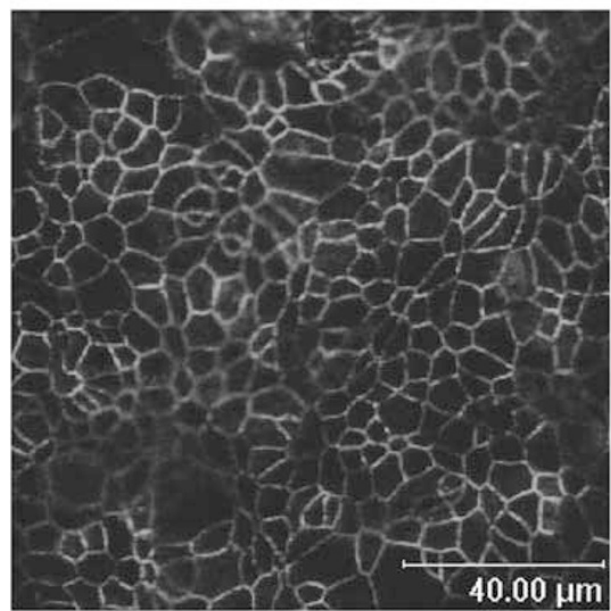

IL-13+Ly $5 \mu \mathrm{M}$

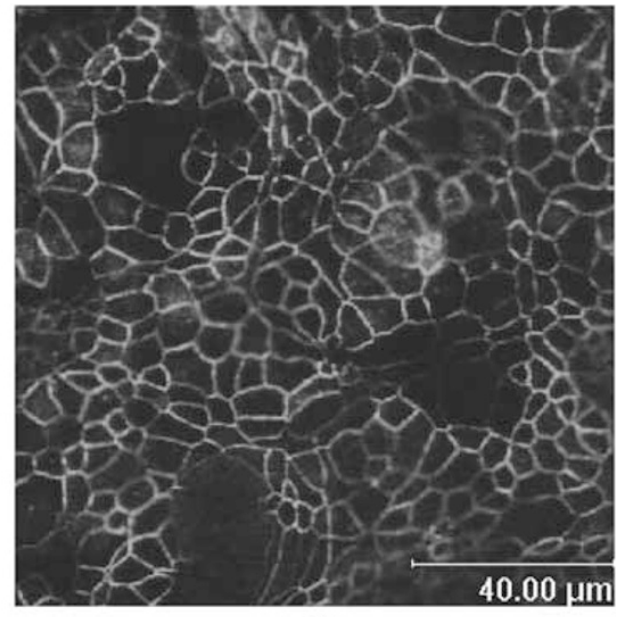

IL-13

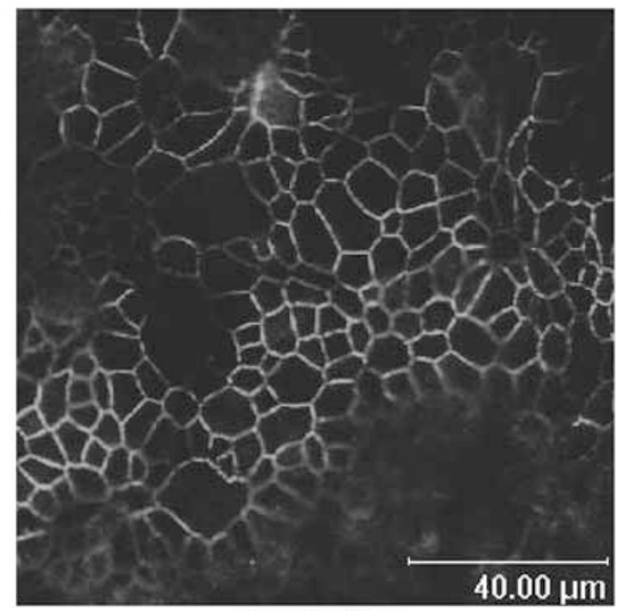

IL-13+Ly20 $\mu \mathrm{M}$

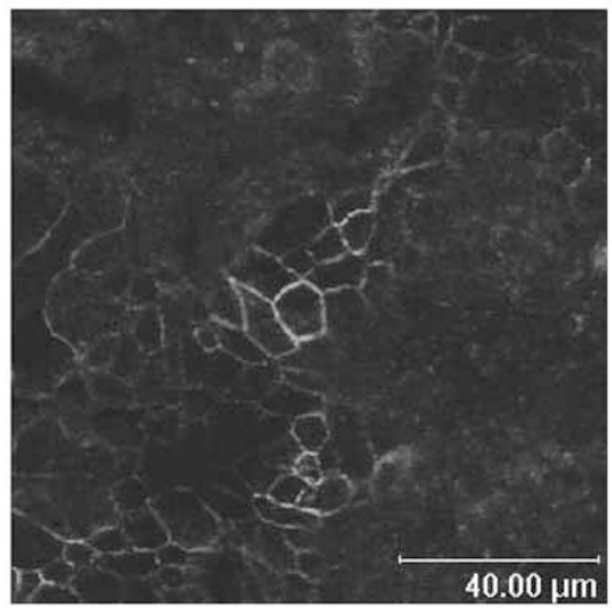

IL-13+Ly $50 \mu \mathrm{M}$

Figure 9 The influence of LY294002 PI3K inhibitor on IL-13 induced changes in claudin 2 and epithelial permeability in T84 cells. Day 15 T84 cell monolayers were exposed to medium plus vehicle (control), IL-13 at $2 \mathrm{ng} / \mathrm{ml}$ (IL-13), IL-13 plus Ly294002 at $5 \mu \mathrm{M}$ (Ly5), $20 \mu \mathrm{M}$ (Ly20) or $50 \mu \mathrm{M}$ (Ly50). (a) Confocal micrographs of claudin 2 immunofluorescent staining showing marked increase in staining in response to IL-13 or IL13 plus Ly294002 at $5 \mu \mathrm{M}$ (Ly5). The IL-13-induced increase in claudin 2 was reduced in the presence of Ly294002 at $20 \mu \mathrm{M}$ (Ly20) and virtually inhibited, appearing similar to the control, with Ly294002 at $50 \mu \mathrm{M}$ (Ly50). (b) Western blots of whole cellular protein lysates show increased expression of claudin 2 with IL-13 alone and a dose-dependent inhibition of claudin 2 induction with Ly294002. (c) Permeability to FITClabelled $4 \mathrm{kDa}$ dextran increases with IL-13 but shows no significant change with inhibitor. (d) The reduction in TER after cytokine exposure is partially reversed by Ly294002, $\left({ }^{*} P<0.001\right.$ for $50 \mu \mathrm{M}$ Ly50, $n=6$ ). (e) Western blots of lysates from cells exposed for 10 min to vehicle alone (Cont) or IL-13 \pm inhibitor, then blotted sequentially for p-Akt, total Akt or cytokeratin 19. Cells were preincubated in inhibitor for 10 min prior to the start of the experiment. IL-13 increases phospho-Akt and Ly294002 inhibits the appearance of phospho-Akt at this time point. 
b
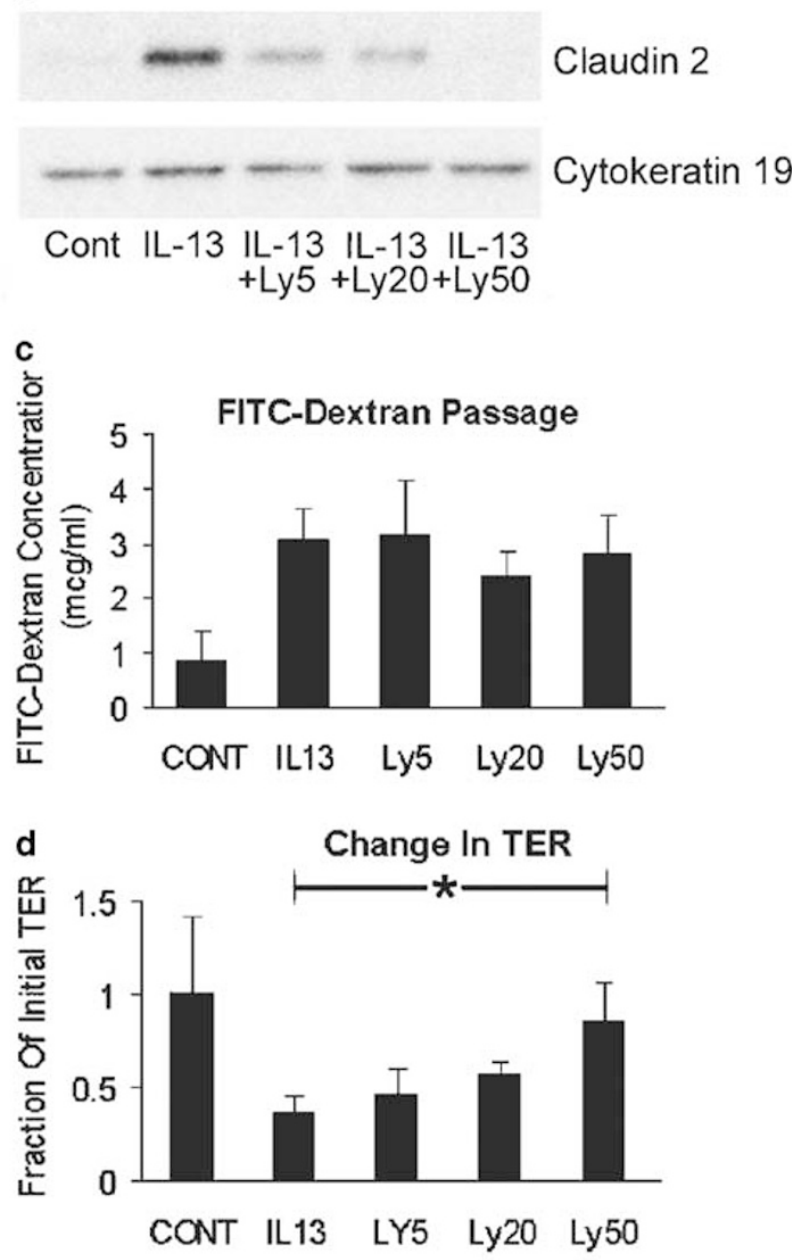

e

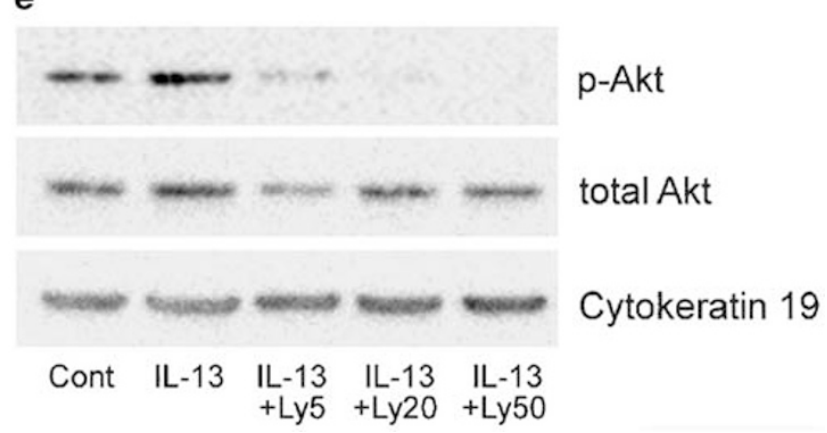

Figure 9 Continued.

but showed marked increases in claudin 2 that correlated with reductions in TER that fit with experiments attributing increases in ion permeability to claudin 2 (see above), although more studies are needed to explore the effect of IL-13 on other proteins involved in the regulation of gut epithelial permeability.

In contrast to IL-13, TNF $\alpha / \mathrm{IFN} \gamma$ treatment produced loss of junctional staining for claudin 3 and particularly claudin 4 , where the staining was seen clearly down the basolateral cell surfaces in an extrajunctional pattern, with a reduction in claudin 2. Loss of claudin 4 maybe significant as this claudin decreases permeability to sodium ions relative to chloride ${ }^{66}$ and a contributing role for claudin 3 cannot be excluded since modification by phosphorylation of claudin 3 has recently been implicated in the regulation of TER in ovarian carcinoma cells. ${ }^{65}$ These data suggest that the decrease in TER in response to TNF $\alpha / \mathrm{IFN} \gamma$ occurs by a mechanism distinct from that induced by IL-13. Rather than induction of claudin-2, it appears that $\mathrm{TNF} \alpha / \mathrm{IFN} \gamma$ may cause a more global tight junction disruption with removal of claudin 4 and other proteins from the tight junction. Many previous studies have been published on the effects of TNF $\alpha /$ IFN $\gamma$ on gut epithelial cell barriers ${ }^{29,30,75-81}$ although few studies are published on the response of claudins to inflammatory cytokines. ${ }^{80-82}$ TNF $\alpha / \mathrm{IFN} \gamma$ was reported to promote internalisation of junction adhesion molecule 1, occludin, and claudins 1 and 4 that correlated with large decreases in TER, increases in the passage of $3 \mathrm{kDa}$ FITC-dextran, but no significant changes in protein detection levels on Western blots. ${ }^{80,81}$ Our results for claudin 4 are very similar, except that the degree of cytoplasmic staining is not so striking, perhaps because our study utilised a lower dose of TNF $\alpha$.

Alteration in the localisation of claudins $3 / 4$ in our experiments, or occludin and $\mathrm{ZO}-1,{ }^{77}$ in response to $\mathrm{TNF} \alpha / \mathrm{IFN} \gamma,{ }^{30}$ may involve actomyosin contraction. $^{83,84} \mathrm{TNF} \alpha / \mathrm{IFN} \gamma$ treatment induced a decrease in the TER of Caco-2 monolayers that was associated with increased myosin II regulatory light chain (MLC) phosphorylation and conversely, inhibition of myosin light chain kinase (MLCK) reduced MLC phosphorylation, increased TER and reduced paracellular mannitol flux. ${ }^{85}$ In addition, TNF $\alpha /$ IFN $\gamma$ was shown to promote MLCK mRNA and protein expression ${ }^{81,86}$ suggesting that MLCK is inducible by these cytokines. In small intestinal villi and differentiating postconfluent Caco-2 monolayers, MLCK1 was the isoform specifically associated with regulation of tight junction permeability. ${ }^{87} \mathrm{TNF} \alpha$-induced cytoskeletal rearrangements driven by MLCK activity may be important for further responses to TNF $\alpha$ in gut epithelial cells as this mechanism has been shown to be necessary for $\mathrm{TNF} \alpha$-dependent $\mathrm{NF} \kappa \mathrm{B}$ activation and amplification of prosurvival signals in endothelial cells. ${ }^{88}$

Treatment of T84 cells with TNF $\alpha / \mathrm{IFN} \gamma$ or IL-13 produced a marked increase in the passage of the uncharged solute FITC-dextran. In previous work, where claudins have been overexpressed, marked alterations in the TER were observed, with no changes in the passage of uncharged solutes such as mannitol, lactulose or FITC-dextran, suggesting that claudins do not influence this pathway. ${ }^{63,64,66} \mathrm{In}$ addition, occludin mutants have been shown to be capable of increasing the passage of uncharged molecules without influencing the TER ${ }^{89}$ attesting 

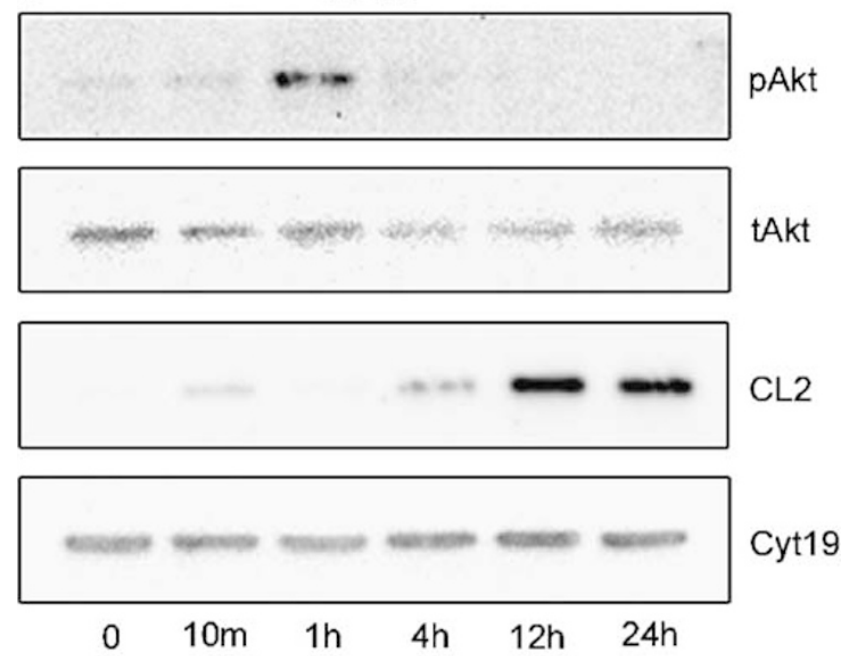

b
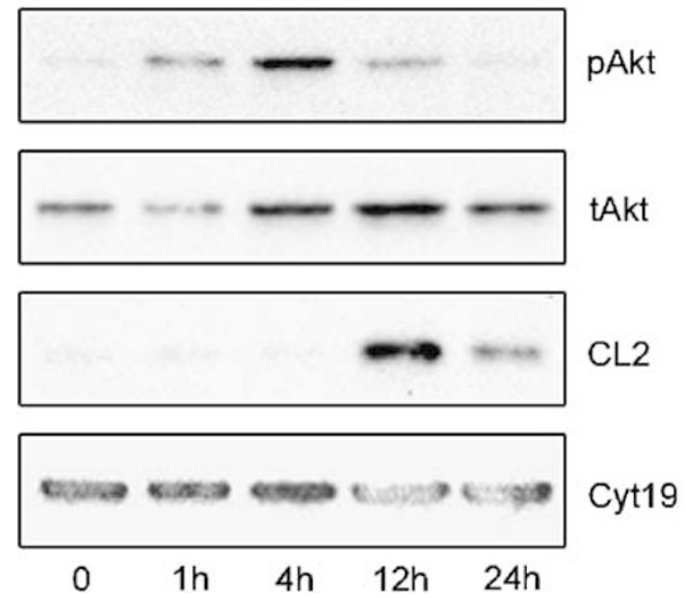

Figure 10 Western blots of T84 cells showing the kinetics of phospho-Akt activation in relation to claudin 2 expression. The 15-day T84 monolayers were blotted sequentially for claudin 2, p-Akt, total Akt or cytokeratin 19 after $16 \mathrm{~h}$ in serum- and insulinfree medium followed by stimulation with IL-13 $(2 \mathrm{ng} / \mathrm{ml})$ for 0 , $10 \mathrm{~min}, 1,4,12$ and $24 \mathrm{~h}$ or $\mathrm{LiCl}(20 \mathrm{mM})$ for $0,1,4,12$ and $24 \mathrm{~h}$ prior to solubilisation. IL-13 (a) promotes the appearance of claudin 2 with similar kinetics to LiCl (b). The increase in claudin 2 is preceded by an increase in p-Akt with both treatments. Note immunoreactivity to p-Akt at 0 and $10 \mathrm{~min}$ in Figure 10a appear weaker compared with the blot in Figure 9e owing to removal of insulin $^{60,61}$ from the medium. The relative signals are similar in both Figures $9 \mathrm{e}$ and 10a.

to the subtlety and complexity of regulation of the junction and suggesting that other components of the tight junction, in addition to claudins, are affected in response to these cytokines.

We found that inhibition of PI3K by LY294002 restored the IL-13-mediated drop in TER, confirming previous work $^{57}$ without affecting the permeability to FITC-dextran. However importantly, LY294002 also inhibited the expression of claudin 2 protein, again suggesting that claudin 2 expression and TER are related. IL-13 has been shown
Table 3 Relative quantitation of reverse transcriptase-mediated PCR for claudin 2 transcripts in IL-13-treated human colonic T84-cell monolayers

\begin{tabular}{lccc}
\hline \multirow{2}{*}{ Samples } & \multicolumn{3}{c}{ CT values (median (range)) } \\
\cline { 2 - 4 } & Control $(\mathrm{n}=3)$ & $I L-13^{*}(\mathrm{n}=3)$ & $I L-13^{* *}(\mathrm{n}=3)$ \\
\hline Ly294002 & & & \\
CL 2 & $26(25-26)$ & $24(23-24)$ & $27(24-28)$ \\
GAPDH & $18(17-18)$ & $17(17-18)$ & $18(17-18)$ \\
UBC & $22(21-22)$ & $22(22-23)$ & $23(22-23)$ \\
HK mean & $20(19-20)$ & $20(20)$ & $20(20)$ \\
Normalized CT & $6(5-7)$ & $4(4)$ & $7(4-8)$ \\
Rel. abundance & $1(0.4-1.5)$ & $4(3-4)$ & $0.3(0.2-3)$ \\
& & &
\end{tabular}

The data shows a relative increase in claudin 2 transcript numbers in the presence of IL-13, compared with control and with inhibition by Ly294002.

*IL-13 vs control, $P=0.049 ;{ }^{*} \mathrm{IL}-13$ vs $\mathrm{IL}-13+\mathrm{LY} 294002, P=0.05$; **IL-13+LY294002 vs control, $P=0.513$.

Table 4 Relative quantitation of reverse transcriptase-mediated PCR for claudin 2 transcripts in diseased and normal human colonic epithelium

\begin{tabular}{lccc}
\hline \multirow{2}{*}{ Cases } & \multicolumn{3}{c}{ CT values (median (range)) } \\
\cline { 2 - 4 } & Normal $^{*}(\mathrm{n}=5)$ & $U C^{* *}(\mathrm{n}=4)$ & $C D^{* * *}(\mathrm{n}=4)$ \\
\hline CL 2 & $44(39-45)$ & $33.5(31-35)$ & $35.5(31-44)$ \\
GAPDH & $28(23-31)$ & $23(22-23)$ & $27(23-27)$ \\
UBC & $26(20-28)$ & $20.5(20-22)$ & $24(24-27)$ \\
HK Mean & $27(22-29)$ & $22(21-23)$ & $25(23-26)$ \\
Normalized CT & $17(16-17)$ & $11.5(9-13)$ & $11.5(6-18)$ \\
Rel. abundance & $1(1-2)$ & $48(16-256)$ & $48(0.5-2056)$ \\
\end{tabular}

The data shows a relative increase in transcripts in IBD.

${ }^{*}$ Normal vs IBD, $P=0.004 ; *{ }^{*} \mathrm{UC}$ vs normal, $P=0.012 ; * *{ }^{*} \mathrm{CD}$ vs normal, $P=0.22$.

to activate the PI3K signalling pathway through recruitment of the insulin receptor substrate family ${ }^{55,56}$ and, in addition, the PI3K inhibitor, LY294002 has been shown to reverse the oxidativestress induced disruption of tight junctions in CaCo2 cells. ${ }^{90}$ As we did not see reversal of the IL13-mediated increase in the passage of FITC-dextran with LY294002, this also suggests separable regulation of the TER and the passage of uncharged molecules, the latter possibly regulated by occludin (see above). As PI3K has been shown to bind to occludin C-terminus ${ }^{90,91}$ this result was unexpected but it implies that the two mechanisms are separable or may have different sensitivities to PI3K inhibition in T84 cells.

Our results suggested that the response to IL-13 is mediated at least in part by an increase in the number of claudin 2 transcripts, which could be a result of increases in mRNA stability or transcription. Activation of the Janus kinase STAT6 transcription cascade via IL-13R $\alpha 1 / \mathrm{IL}-4 \mathrm{R} \alpha \mathrm{II}$ receptor dimers ${ }^{56}$ is known to occur in T84 cells in response 
to IL- $13^{57}$ and the claudin 2 distal promoter contains a STAT 6 consensus binding sequence (data not shown), but other evidence suggests that this pathway is probably not involved in the permeability increases measured in response to IL-13. ${ }^{57}$ However, the claudin 2 promoter also contains transcriptionally active binding sites for TCF/Lef-1 and cdx transcription factors. ${ }^{92,93}$ It is possible that claudin 2 transcription is upregulated by a PI3Kmediated mechanism involving p-Akt inhibition of GSK-3 $\beta^{94}$ and stablisation of $\beta$-catenin acting through TCF/Lef- $1,{ }^{95}$ which can also activate transcription of cdx $1 .{ }^{96,97}$ In this context, we observed phosphorylation of Akt in response to IL-13 stimulation. LiCl also caused activation of p-Akt and claudin 2 expression with similar kinetics to Il-13 and may also mediate downstream signalling via $\mathrm{p}$ Akt, Gsk- $3 \beta$ and $\beta$-catenin. ${ }^{60,94,95}$ We did not see evidence of nuclear $\beta$-catenin staining in T84 monolayers stimulated by IL-13 (data not shown); however, more specific methods would be required to establish a role for this pathway. In silico analysis of $\sim 2.0 \mathrm{~kb}$ of claudin 2 genomic DNA sequence, upstream of the coding region, reveals two additional consensus sites for TCF/Lef-1 binding at positions -168 and $-548 \mathrm{bp}$ from the transcription start, in addition to another at $-120 \mathrm{bp}$ previously described $^{93}$ that are potentially sensitive to pAkt/ GSK-3 $\beta$ regulation.

In summary, we have observed that claudins 2, 3 and 4 are altered in inflammatory conditions of the colon, with epithelial claudin 2 protein and mRNA highly expressed compared to normal tissue. Our data suggest that claudin 2 was more highly expressed in UC (see Figure 4, Table 2) and it has recently been reported that mucosal T cells from UC patients make more IL-13 than T cells from normal patients or CD. ${ }^{38}$ We hesitate to suggest that IL-13 is one of the mechanistic drivers of altered claudin 2 expression in IBD since the current literature on levels of IL-13 in IBD is contentious with studies showing both increased ${ }^{38}$ and decreased levels ${ }^{98,99}$ in disease. Our data from a cell culture model of the epithelial barrier indicate that one consequence of increased IL-13 would be to increase permeability, potentially involving increased claudin 2 expression, and that inflammatory cytokines may alter tight junctions via differential effects on claudin proteins.

\section{Acknowledgements}

This work was supported by Medical Research Council, UK Fellowship 43112 to SP, JC and TTM, a grant from The Belmont Trust to TTM, a fellowship from the Academy of Finland, number 51547, to KK and grants from Sigrid Juselius and Maud Kuistila Foundations to KK. We thank Dr Karl Matter for discussions relating to fixing and staining of cells on semipermeable inserts,
Dr Susan Wilson for help with glycolmethacrylate tissue processing, Dr Roger Alston for confocal microscopy instruction and Dr Adrian Bateman for histology advice.

\section{References}

1 Sartor RB. Current concepts of the etiology and pathogenesis of ulcerative colitis and Crohn's disease. Gastroenterol Clin North Am 1995;24:475-507.

2 Meddings JB. Review article: intestinal permeability in Crohn's disease. Aliment Pharmacol Ther 1997; 11(Suppl 3):47-53; discussion 53-56: 47-53.

3 Hollander D. Intestinal permeability, leaky gut, and intestinal disorders. Curr Gastroenterol Rep 1999; 1:410-416.

4 Soderholm JD, Peterson KH, Olaison G, et al. Epithelial permeability to proteins in the noninflamed ileum of Crohn's disease? Gastroenterology 1999;117: $65-72$.

5 Wyatt J, Vogelsang $\mathrm{H}$, Hubl W, et al. Intestinal permeability and the prediction of relapse in Crohn's disease. Lancet 1993;341:1437-1439.

6 Arnott ID, Kingstone K, Ghosh S. Abnormal intestinal permeability predicts relapse in inactive Crohn disease. Scand J Gastroenterol 2000;35:1163-1169.

7 D’Inca R, Di Leo V, Corrao G, et al. Intestinal permeability test as a predictor of clinical course in Crohn's disease. Am J Gastroenterol 1999;94: 2956-2960.

8 Stoll M, Corneliussen B, Costello CM, et al. Genetic variation in DLG5 is associated with inflammatory bowel disease. Nat Genet 2004;36:476-480.

9 Unno N, Fink MP. Intestinal epithelial hyperpermeability. Mechanisms and relevance to disease. Gastroenterol Clin North Am 1998;27:289-307.

10 Collins JE. Classical and Desmosomal Cadherins. In: Malhotra SK (eds). 4th edn. Jai Press Inc.: Greenwich, CT, USA, 1996, pp 75-108.

11 Balda MS, Matter K. Transmembrane proteins of tight junctions. Semin Cell Dev Biol 2000;11:281-289.

12 Garrod DR, Merritt AJ, Nie Z. Desmosomal cadherins. Curr Opin Cell Biol 2002;14:537-545.

13 Wheelock MJ, Johnson KR. Cadherins as modulators of cellular phenotype. Annu Rev Cell Dev Biol 2003;19: 207-235.

14 Gonzalez-Mariscal L, Betanzos A, Nava P, et al. Tight junction proteins. Prog Biophys Mol Biol 2003;81: $1-44$.

15 Getsios S, Huen AC, Green KJ. Working out the strength and flexibility of desmosomes. Nat Rev Mol Cell Biol 2004;5:271-281.

16 Cereijido M, Gonzalez-Mariscal L, Contreras RG. Epithelial tight junctions. Am Rev Respir Dis 1988; 138:S17-S21.

17 Dragsten PR, Blumenthal R, Handler JS. Membrane asymmetry in epithelia: is the tight junction a barrier to diffusion in the plasma membrane? Nature 1981; 294:718-722.

18 van Meer G, Simons K. The function of tight junctions in maintaining differences in lipid composition between the apical and the basolateral cell surface domains of MDCK cells. EMBO J 1986;5:1455-1464.

19 Matter K, Balda MS. Signalling to and from tight junctions. Nat Rev Mol Cell Biol 2003;4:225-236. 
20 Tsukita S, Furuse M. Claudin-based barrier in simple and stratified cellular sheets. Curr Opin Cell Biol 2002;14:531-536.

21 Turksen K, Troy TC. Barriers built on claudins. J Cell Sci 2004;117:2435-2447.

22 Suzuki F, Nagano T. Three-dimensional model of tight junction fibrils based on freeze-fracture images. Cell Tissue Res 1991;264:381-384.

23 Furuse M, Sasaki H, Fujimoto K, et al. A single gene product, claudin-1 or -2 , reconstitutes tight junction strands and recruits occludin in fibroblasts. J Cell Biol 1998;143:391-401.

24 Morita K, Sasaki H, Furuse M, et al. Endothelial claudin: claudin-5/TMVCF constitutes tight junction strands in endothelial cells. J Cell Biol 1999;147: 185-194.

25 Schmitz H, Barmeyer C, Fromm M, et al. Altered tight junction structure contributes to the impaired epithelial barrier function in ulcerative colitis. Gastroenterology 1999;116:301-309.

26 Gassler N, Rohr C, Schneider A, et al. Inflammatory bowel disease is associated with changes of enterocytic junctions. Am J Physiol Gastrointest Liver Physiol 2001;281:G216-G228.

27 Kucharzik T, Walsh SV, Chen J, et al. Neutrophil transmigration in inflammatory bowel disease is associated with differential expression of epithelial intercellular junction proteins. Am J Pathol 2001;159: 2001-2009.

28 Burgel N, Bojarski C, Mankertz J, et al. Mechanisms of diarrhea in collagenous colitis. Gastroenterology 2002; 123:433-443.

29 Madara JL, Stafford J. Interferon-gamma directly affects barrier function of cultured intestinal epithelial monolayers. J Clin Invest 1989;83:724-727.

30 Walsh SV, Hopkins AM, Nusrat A. Modulation of tight junction structure and function by cytokines. Adv Drug Deliv Rev 2000;41:303-313.

31 Hollande F, Blanc EM, Bali JP, et al. HGF regulates tight junctions in new nontumorigenic gastric epithelial cell line. Am J Physiol Gastrointest Liver Physiol 2001;280:G910-G921.

32 Martin TA, Watkins G, Mansel RE, et al. Hepatocyte growth factor disrupts tight junctions in human breast cancer cells. Cell Biol Int 2004;28:361-371.

33 Singh AB, Harris RC. Epidermal growth factor receptor activation differentially regulates claudin expression and enhances transepithelial resistance in MadinDarby canine kidney cells. J Biol Chem 2004;279: 3543-3552.

34 MacDonald TT, Monteleone G. IL-12 and Th1 immune responses in human Peyer's patches. Trends Immunol 2001;22:244-247.

35 Bouma G, Strober W. The immunological and genetic basis of inflammatory bowel disease. Nat Rev Immunol 2003;3:521-533.

36 Breese EJ, Michie CA, Nicholls SW, et al. Tumor necrosis factor alpha-producing cells in the intestinal mucosa of children with inflammatory bowel disease. Gastroenterology 1994;106:1455-1466.

37 Fuss IJ, Neurath $\mathrm{M}$, Boirivant $\mathrm{M}$, et al. Disparate CD4+ lamina propria (LP) lymphokine secretion profiles in inflammatory bowel disease. Crohn's disease LP cells manifest increased secretion of IFN-gamma, whereas ulcerative colitis LP cells manifest increased secretion of IL-5. J Immunol 1996; 157:1261-1270.
38 Fuss IJ, Heller F, Boirivant M, et al. Nonclassical CD1drestricted NK T cells that produce IL-13 characterize an atypical Th2 response in ulcerative colitis. J Clin Invest 2004;113:1490-1497.

39 Madara JL, Stafford J, Dharmsathaphorn K, et al. Structural analysis of a human intestinal epithelial cell line. Gastroenterology 1987;92:1133-1145.

40 Madara JL, Dharmsathaphorn K. Occluding junction structure-function relationships in a cultured epithelial monolayer. J Cell Biol 1985;101:2124-2133.

41 Luciano L, Reale E, Rechkemmer G, et al. Structure of zonulae occludentes and the permeability of the epithelium to short-chain fatty acids in the proximal and the distal colon of guinea pig. J Membr Biol 1984;82:145-156.

42 Welsh MJ, Smith PL, Fromm M, et al. Crypts are the site of intestinal fluid and electrolyte secretion. Science 1982;218:1219-1221.

43 Powell DW. Dogma destroyed: colonic crypts absorb. J Clin Invest 1995;96:2102-2103.

44 Britten KM, Howarth PH, Roche WR. Immunohistochemistry on resin sections: a comparison of resin embedding techniques for small mucosal biopsies. Biotech Histochem 1993;68:271-280.

45 Flint N, Cove FL, Evans GS. A low temperature method for the isolation of small-intestinal epithelium along the crypt-villus axis. Biochem J 1991;280: 331-334.

46 Laemmli UK. Cleavage of structural proteins during the assembly of the head of bacteriophage T4. Nature 1970;227:680-685.

47 Cereijido M, Gonzalez-Mariscal L, Borboa L. Occluding junctions and paracellular pathways studied in monolayers of MDCK cells. J Exp Biol 1983;106: 205-215.

48 Matter K, Balda MS. Functional analysis of tight junctions. Methods 2003;30:228-234.

49 Fish SM, Proujansky R, Reenstra WW. Synergistic effects of interferon gamma and tumour necrosis factor alpha on T84 cell function. Gut 1999;45:191-198.

50 Potten CS, Kellett M, Roberts SA, et al. Measurement of in vivo proliferation in human colorectal mucosa using bromodeoxyuridine. Gut 1992;33:71-78.

51 Bromley M, Rew D, Becciolini A, et al. A comparison of proliferation markers (BrdUrd, Ki-67, PCNA) determined at each cell position in the crypts of normal human colonic mucosa. Eur J Histochem 1996;40: 89-100.

52 Franklin WA, McDonald GB, Stein HO, et al. Immunohistologic demonstration of abnormal colonic crypt cell kinetics in ulcerative colitis. Hum Pathol 1985; 16:1129-1132.

53 Delpre G, Avidor I, Steinherz R, et al. Ultrastructural abnormalities in endoscopically and histologically normal and involved colon in ulcerative colitis. Am J Gastroenterol 1989;84:1038-1046.

54 Leonard WJ, O'Shea JJ. Jaks and STATs: biological implications. Annu Rev Immunol 1998;16:293-322.

55 Nelms K, Keegan AD, Zamorano J, et al. The IL-4 receptor: signaling mechanisms and biologic functions. Annu Rev Immunol 1999;17:701-738.

56 Kelly-Welch AE, Hanson EM, Boothby MR, et al. Interleukin-4 and interleukin-13 signaling connections maps. Science 2003;300:1527-1528.

57 Ceponis PJ, Botelho F, Richards CD, et al. Interleukins 4 and 13 increase intestinal epithelial permeability by a phosphatidylinositol 3-kinase pathway. Lack of 
evidence for STAT 6 involvement. J Biol Chem 2000; 275:29132-29137.

58 Hallmann D, Trumper K, Trusheim H, et al. Altered signaling and cell cycle regulation in embryonal stem cells with a disruption of the gene for phosphoinositide 3-kinase regulatory subunit p85alpha. J Biol Chem 2003;278:5099-5108.

59 Scheid MP, Woodgett JR. Unravelling the activation mechanisms of protein kinase B/Akt. FEBS Lett 2003;546:108-112.

60 Chalecka-Franaszek E, Chuang DM. Lithium activates the serine/threonine kinase Akt-1 and suppresses glutamate-induced inhibition of Akt-1 activity in neurons. Proc Natl Acad Sci USA 1999;96:8745-8750.

61 Kashour T, Burton T, Dibrov A, et al. Myogenic signaling by lithium in cardiomyoblasts is Akt independent but requires activation of the beta-catenin-Tcf/ Lef pathway. J Mol Cell Cardiol 2003;35:937-951.

62 Anderson JM, Van Itallie CM, Fanning AS. Setting up a selective barrier at the apical junction complex. Curr Opin Cell Biol 2004;16:140-145.

63 Furuse M, Furuse K, Sasaki H, et al. Conversion of zonulae occludentes from tight to leaky strand type by introducing claudin-2 into Madin-Darby canine kidney I cells. J Cell Biol 2001;153:263-272.

64 Amasheh S, Meiri N, Gitter AH, et al. Claudin-2 expression induces cation-selective channels in tight junctions of epithelial cells. J Cell Sci 2002;115: 4969-4976.

65 D’Souza T, Agarwal R, Morin PJ. Phosphorylation of claudin-3 at threonine 192 by PKA regulates tight junction barrier function in ovarian cancer cells. J Biol Chem 2005 [Epub ahead of print].

66 Van Itallie C, Rahner C, Anderson JM. Regulated expression of claudin-4 decreases paracellular conductance through a selective decrease in sodium permeability. J Clin Invest 2001;107:1319-1327.

67 Van Itallie CM, Fanning AS, Anderson JM. Reversal of charge selectivity in cation or anion-selective epithelial lines by expression of different claudins. Am J Physiol Renal Physiol 2003;285:F1078-F1084.

68 Colegio OR, Van Itallie C, Rahner C, et al. Claudin extracellular domains determine paracellular charge selectivity and resistance but not tight junction fibril architecture. Am J Physiol Cell Physiol 2003;284: C1346-C1354.

69 Grencis RK, Bancroft AJ. Interleukin-13: a key mediator in resistance to gastrointestinal-dwelling nematode parasites. Clin Rev Allergy Immunol 2004; 26:51-60.

70 Escaffit F, Boudreau F, Beaulieu JF. Differential expression of claudin-2 along the human intestine: Implication of GATA-4 in the maintenance of claudin2 in differentiating cells. J Cell Physiol 2005;203: 15-26.

71 Dharmsathaphorn K, McRoberts JA, Mandel KG, et al. A human colonic tumor cell line that maintains vectorial electrolyte transport. Am J Physiol 1984;246: G204-G208.

72 Fihn BM, Jodal M. Permeability of the proximal and distal rat colon crypt and surface epithelium to hydrophilic molecules. Pflugers Arch 2001;441: 656-662.

73 Sanders SE, Madara JL, McGuirk DK, et al. Assessment of inflammatory events in epithelial permeability: a rapid screening method using fluorescein dextrans. Epithelial Cell Biol 1995;4:25-34.
74 Zund G, Madara JL, Dzus AL, et al. Interleukin-4 and interleukin-13 differentially regulate epithelial chloride secretion. J Biol Chem 1996;271:7460-7464.

75 McKay DM, Singh PK. Superantigen activation of immune cells evokes epithelial (T84) transport and barrier abnormalities via IFN-gamma and TNF alpha: inhibition of increased permeability, but not diminished secretory responses by TGF-beta2. J Immunol 1997;159:2382-2390.

76 Schmitz H, Fromm M, Bentzel CJ, et al. Tumor necrosis factor-alpha (TNFalpha) regulates the epithelial barrier in the human intestinal cell line HT-29/B6. J Cell Sci 1999;112:137-146.

77 Youakim A, Ahdieh M. Interferon-gamma decreases barrier function in T84 cells by reducing ZO-1 levels and disrupting apical actin. Am J Physiol 1999;276: G1279-G1288.

78 Soler AP, Marano CW, Bryans M, et al. Activation of NF-kappaB is necessary for the restoration of the barrier function of an epithelium undergoing TNF-alphainduced apoptosis. Eur J Cell Biol 1999;78:56-66.

79 Sugi K, Musch MW, Field M, et al. Inhibition of $\mathrm{Na}+, \mathrm{K}+$-ATPase by interferon gamma down-regulates intestinal epithelial transport and barrier function. Gastroenterology 2001;120:1393-1403.

80 Bruewer M, Luegering A, Kucharzik T, et al. Proinflammatory cytokines disrupt epithelial barrier function by apoptosis-independent mechanisms. J Immunol 2003;171:6164-6172.

81 Wang F, Graham WV, Wang Y, et al. Interferon-gamma and tumor necrosis factor-alpha synergize to induce intestinal epithelial barrier dysfunction by up-regulating myosin light chain kinase expression. Am J Pathol 2005;166:409-419.

82 Kinugasa T, Sakaguchi T, Gu X, et al. Claudins regulate the intestinal barrier in response to immune mediators. Gastroenterology 2000;118:1001-1011.

83 Turner JR. 'Putting the squeeze' on the tight junction: understanding cytoskeletal regulation. Semin Cell Dev Biol 2000;11:301-308.

84 Clayburgh DR, Shen L, Turner JR. A porous defense: the leaky epithelial barrier in intestinal disease. Lab Invest 2004;84:282-291.

85 Zolotarevsky Y, Hecht G, Koutsouris A, et al. A membrane-permeant peptide that inhibits MLC kinase restores barrier function in in vitro models of intestinal disease. Gastroenterology 2002;123:163-172.

86 Ma TY, Boivin MA, Ye D, et al. Mechanism of TNF\{alpha\} modulation of Caco-2 intestinal epithelial tight junction barrier: role of myosin light-chain kinase protein expression. Am J Physiol Gastrointest Liver Physiol 2005;288:G422-G430.

87 Clayburgh DR, Rosen S, Witkowski ED, et al. A differentiation-dependent splice variant of myosin light chain kinase, MLCK1, regulates epithelial tight junction permeability. J Biol Chem 2004;279:5550655513.

88 Wadgaonkar R, Linz-McGillem L, Zaiman AL, et al. Endothelial cell myosin light chain kinase (MLCK) regulates TNFalpha-induced NFkappaB activity. J Cell Biochem 2005;94:351-364.

89 Balda MS, Flores-Maldonado C, Cereijido M, et al. Multiple domains of occludin are involved in the regulation of paracellular permeability. J Cell Biochem 2000;78:85-96.

90 Sheth P, Basuroy S, Li C, et al. Role of phosphatidylinositol 3-kinase in oxidative stress-induced disrup- 
tion of tight junctions. J Biol Chem 2003;278:4923949245.

91 Nusrat A, Chen JA, Foley CS, et al. The coiled-coil domain of occludin can act to organize structural and functional elements of the epithelial tight junction. J Biol Chem 2000;275:29816-29822.

92 Sakaguchi T, Gu X, Golden HM, et al. Cloning of the human claudin-2 5'-flanking region revealed a TATAless promoter with conserved binding sites in mouse and human for caudal-related homeodomain proteins and hepatocyte nuclear factor-1alpha. J Biol Chem 2002;277:21361-21370.

93 Mankertz J, Hillenbrand B, Tavalali S, et al. Functional crosstalk between Wnt signaling and Cdx-related transcriptional activation in the regulation of the claudin-2 promoter activity. Biochem Biophys Res Commun 2004;314:1001-1007.

94 Cross DA, Alessi DR, Cohen $\mathrm{P}$, et al. Inhibition of glycogen synthase kinase-3 by insulin mediated by protein kinase B. Nature 1995;378:785-789.
95 van Noort $\mathrm{M}$, Meeldijk J, van der ZR, et al. Wnt signaling controls the phosphorylation status of beta-catenin. J Biol Chem 2002;277:1790117905.

96 Lickert H, Domon C, Huls G, et al. Wnt/(beta)-catenin signaling regulates the expression of the homeobox gene $\mathrm{Cdx} 1$ in embryonic intestine. Development 2000;127:3805-3813.

97 Domon-Dell C, Freund JN. Stimulation of Cdx1 by oncogenic beta-catenin/Tcf4 in colon cancer cells; opposite effect of the CDX2 homeoprotein. FEBS Lett 2002;518:83-87.

98 Kadivar K, Ruchelli ED, Markowitz JE, et al. Intestinal interleukin-13 in pediatric inflammatory bowel disease patients. Inflamm Bowel Dis 2004;10: 593-598.

99 Vainer B, Nielsen OH, Hendel J, et al. Colonic expression and synthesis of interleukin 13 and interleukin 15 in inflammatory bowel disease. Cytokine 2000;12:1531-1536. 